\title{
A robust low-level cloud and clutter discrimination method for ground-based millimeter-wavelength cloud radar
}

\author{
Xiaoyu Hu${ }^{1}$, Jinming $\mathrm{Ge}^{1}$, Jiajing Du${ }^{1}$, Qinghao $\mathrm{Li}^{1}$, Jianping Huang ${ }^{1}$, and Qiang $\mathrm{Fu}^{2}$ \\ ${ }^{1}$ Key Laboratory for Semi-Arid Climate Change of the Ministry of Education and College of Atmospheric Sciences, \\ Lanzhou University, Lanzhou, 730000, China \\ ${ }^{2}$ Department of Atmospheric Sciences, University of Washington, Seattle, WA 98105, USA
}

Correspondence: Jinming Ge (gejm@1zu.edu.cn)

Received: 13 June 2020 - Discussion started: 24 September 2020

Revised: 30 December 2020 - Accepted: 25 January 2021 - Published: 3 March 2021

\begin{abstract}
Low-level clouds play a key role in the energy budget and hydrological cycle of the climate system. The accurate long-term observation of low-level clouds is essential for understanding their climate effect and model constraints. Both ground-based and spaceborne millimeter-wavelength cloud radars can penetrate clouds but the detected low-level clouds are always contaminated by clutter, which needs to be removed. In this study, we develop an algorithm to accurately separate low-level clouds from clutter for groundbased cloud radar using multi-dimensional probability distribution functions along with the Bayesian method. The radar reflectivity, linear depolarization ratio, spectral width, and their dependence on the time of the day, height, and season are used as the discriminants. A low-pass spatial filter is applied to the Bayesian undecided classification mask by considering the spatial correlation difference between clouds and clutter. The final feature mask result has a good agreement with lidar detection, showing a high probability of detection rate $(98.45 \%)$ and a low false alarm rate $(0.37 \%)$. This algorithm will be used to reliably detect low-level clouds at the Semi-Arid Climate and Environment Observatory of Lanzhou University (SACOL) site for the study of their climate effect and the interaction with local abundant dust aerosol in semi-arid regions.
\end{abstract}

\section{Introduction}

Clouds play a crucial role in the Earth-atmosphere system by reflecting solar radiation back to space and trapping outgoing terrestrial radiation (Bony et al., 2015; Fu et al., 2000, 2018;
Quaas et al., 2016). Clouds also produce precipitation to release large amounts of latent heat into the atmosphere, compensating the atmospheric radiative cooling, which is consequently closely related to the hydrological cycle and global distribution of water resources (Bala et al., 2010; Fu et al., 2002; Nuijens et al., 2017). Low-level clouds are primarily composed of water droplets and have an overall cooling effect on the climate system. In the context of global warming, tropical low-level cloud amount decreases because of stronger surface turbulent fluxes and drier planetary boundary layer, generating a positive climate feedback through a reduction in the reflection of shortwave radiation (Brient and Bony, 2012; Zhang et al., 2018), while the liquid water path of low-level clouds over midlatitudes to high latitudes tends to increase due to a reduced conversion efficiency of liquid water to ice and precipitation, which leads to a negative feedback (Ceppi et al., 2016; Terai et al., 2016). However, the magnitude of these low-level cloud feedbacks responds inconsistently in different climate models, producing a wide range of equilibrium climate sensitivity (Mace and Berry, 2017; Watanabe et al., 2018; Zelinka et al., 2020). To reduce this uncertainty, accurate long-term observations are important to characterize low-level clouds and understand their climate feedbacks (Garrett and Zhao, 2013; Toll et al., 2019; Turner et al., 2007).

The ground-based cloud radars can probe the vertical structure of low-level clouds in high temporal-vertical resolution, including multi-layer clouds (Kim et al., 2011; van der Linden et al., 2015). Due to substantial progress in the development and application of ground-based radars, there are increasing numbers of ground-based millimeter-wavelength 
cloud radars (MMCRs) being deployed all over the world (Arulraj and Barros, 2017; Huo et al., 2020; Kollias et al., 2019). Their short wavelengths allow the radars to detect clouds with small droplets and infer the microphysical and dynamical cloud processes (Kollias et al., 2007a). A Kaband zenith radar (KAZR) has been continuously running at the Semi-Arid Climate and Environment Observatory of Lanzhou University (SACOL) since 2013 (Ge et al., 2018, 2019; Huang et al., 2008b) to investigate cloud properties over the site. SACOL is located in the downwind dust transport path about $2000 \mathrm{~km}$ to the east of the Taklimakan Desert (i.e., one of the most important global sources of atmospheric dust) (Ge et al., 2014; Huang et al., 2007; Jing Su et al., 2008). Low-level clouds in this semi-arid region with abound dust aerosols acting as cloud condensation nuclei may contain a larger number of small droplets (Givati and Rosenfeld, 2004; Huang et al., 2006), which may reflect more shortwave radiation, merge more slowly to fall as precipitation (Huang et al., 2014; Xue et al., 2008) and thus affect the regional energy budget and water cycle in specific ways. Therefore, cloud observations are vital to understand their effects on the local fragile dryland ecosystem (Fu and Feng, 2014; Huang et al., 2017, 2018, 2020). MMCR-observed cloud echoes in the lowest $3 \mathrm{~km}$ a.g.l. are often contaminated by unwanted clutter, mostly insects for midlatitude continents (Clothiaux et al., 2000), presenting non-Rayleigh scattering at millimeter wavelength with their large physical size, which need to be removed for the low-level cloud research.

Clouds and clutter show distinguishable morphologies in radar spectra because insects are point targets with wing beat, while clouds are distributed targets. Accordingly, they can be well detected with the radar spectral processing (Luke et al., 2008; Williams et al., 2018). Clutter is generally more non-spherical than cloud droplets, which can lead to a relatively larger linear depolarization ratio (LDR) value compared to clouds, and thus LDR is also a widely used variable in moment data to separate clouds from clutter (Görsdorf et al., 2015; Martner and Moran, 2001; Oh et al., 2018; Rico-Ramirez and Cluckie, 2008). Although a simple LDR threshold can remove a large part of the clutter, not all the radar range bins with high LDR are clutter. For example, the non-spherical melting hydrometeors also generate a significant LDR peak in the melting layer (Kowalewski and Peters, 2010). Furthermore, the threshold fails to separate clutter from hydrometeors when its LDR probability density function (PDF) curves are in the overlapping area. Instead of a single LDR threshold, using more attributes to build multi-dimensional PDFs can adequately describe the different properties of clouds and clutter in multi-dimensional space and thereby decrease the overlapping region and reduce the fraction of ambiguous classifications. For instance, Golbon-Haghighi et al. (2016) used three-dimensional PDFs and $2 \mathrm{~d}$ training data to successfully identify fixed clutter such as buildings and trees for weather radar. The latest Cloud-Aerosol Lidar and Infrared Pathfinder
Satellite Observation (CALIPSO) cloud-aerosol discrimination algorithm uses five different parameters to build multidimensional PDFs and improves the previous classifications (Liu et al., 2019). However, samples are more scattered in higher-dimensional space and are less likely to capture the characteristics of various insect clutter, for example, which have unique yet complicated behavior, using short-term data. To clearly characterize the insect's behavior, a large amount of long-term training data is required to build an accurate multi-dimensional PDF for such clutter.

In this study, we develop a robust algorithm to distinguish low-level clouds from clutter. We first remove the background noise, precipitation and melting layer from radar measurement. We then examine cloud radar observations and select discriminants using radar reflectivity, LDR, and spectral width (SW). Next, we utilize 1-year micropulse lidar (MPL) data to establish the multi-dimensional PDFs for clouds and clutter by noting that lidar is not susceptible to clutter and therefore can provide accurate cloud base measurements. The obtained PDFs are used to train the Bayesian classifier, which can determine whether a radar range gate is a cloud or clutter, by comparing their estimated probabilities. Finally, a low-pass time-space filter is applied to the radar range gates where the Bayesian classifier does not work. Section 2 illustrates radar and lidar observations. The details of the algorithm are described in Sect. 3. Using the presented method, in Sect. 4, several case studies and a 1-year evaluation are shown. Finally, the summary and discussion are provided in Sect. 5.

\section{Instruments and datasets}

The KAZR at the SACOL site $\left(35.57^{\circ} \mathrm{N}, 104.08^{\circ} \mathrm{E}\right)$ is a zenith-pointing dual-polarization cloud radar operating at $35 \mathrm{GHz}$. It uses an extended interaction Klystron (EIK) amplifier with a peak power of $2.2 \mathrm{~kW}$. KAZR has a narrow $\left(0.3^{\circ}\right)$ antenna bandwidth and high temporal $(4.27 \mathrm{~s})$ and vertical $(30 \mathrm{~m})$ resolutions. The cloud radar has been running continuously since 2013 and provides radar reflectivity, Doppler vertical velocity, and SW in each radar range gate from 0.9 to $17.6 \mathrm{~km}$ a.g.l. The LDR is derived as the ratio of cross-polarized reflectivity to co-polarized reflectivity. More details about the KAZR are described in Ge et al. (2017). In this study, we use radar reflectivity, LDR, and SW as discriminants to separate low-level clouds and clutter. The vertical velocity is also used to identity precipitation and melting layer to reduce the potential misclassification. A MPL, working at $527 \mathrm{~nm}$ wavelength with $1 \mathrm{~min}$ temporal and $30 \mathrm{~m}$ vertical resolution, is simultaneously running near the KAZR (Huang et al., 2008a; Xie et al., 2017; Xin et al., 2019). Since lidar is not susceptible to the clutter, the lidar-measured cloud base is accurate, which can be used to establish dependable multi-dimensional PDFs for both clouds and clutter. We use 1-year lidar data (August 2014 to July 2015) to build the 
multi-dimensional PDFs to train the Bayesian classifier (in Sect. 3.2) and another year of data (August 2013 to July 2014) to evaluate the algorithm (in Sect. 4.2). We choose the latter year to build the PDFs because there are more observations available in that year.

\section{Low-level cloud and clutter discrimination algorithm}

The algorithm uses radar-observed variables to describe the different characteristics of clouds and clutter. A probability of a radar range gate to be a cloud or clutter is estimated based on the Bayesian method using the preestablished multi-dimensional PDFs. The step-by-step procedure of the algorithm is summarized in Fig. 1. Before constructing multi-dimensional PDFs of cloud and clutter, the radar echoes including background noise, precipitation and melting layer need to be removed from radar measurement (Sect. 3.1). We then use the simultaneous lidar measurement to distinguish clouds and clutter (Sect. 3.2). Any radar echoes above the lidar cloud base height are considered to be clouds, and those below are clutter. After the multi-dimensional PDFs are created, the Bayesian method is used to estimate the probability of any given radar observation being a cloud or clutter (Sect. 3.3). Although the multi-dimensional PDFs do provide a more comprehensive description of the difference, the Bayesian classifier can only discriminate clouds from clutter when all radar discriminants (radar reflectivity, LDR and SW) are available. The fact that LDR measurement can merely be derived when both co- and cross-polarized reflectivities are available causes a non-negligible amount of undecided classification. A final time-space filter is therefore used to identify these radar range gates, considering that clouds are more spatially correlated than clutter (Sect. 3.4).

\subsection{Removing noise and non-cloud meteorological target}

The radar background noise is firstly removed using the noise-equivalent reflectivity (NER) (Kalapureddy et al., 2018), which is $r^{2} \times Z_{\text {start range, }}$, where $r$ is height and $Z_{\text {start range }}$ is the noise-equivalent reflectivity of the first range gate from the bottom. Here, we use a $Z_{\text {start range }}$ of $-60 \mathrm{dBZ}$, because it fits the radar noise level well after several trials. Figure 2 shows an example of raw and noise-removed reflectivity from 12:08 to 12:29 LT on 28 May 2014. The reflectivity is irregularly dispersed below $2.6 \mathrm{~km}$, which is caused by flying insects, while it is distributed more homogeneously inside the cloud layers above $2.6 \mathrm{~km}$ (Fig. 2a). This is because clutter reflectivity is determined by the size and number of individual insects in a radar range gate and is hardly relevant to its surrounding insects. But the reflectivity inside a cloud is largely controlled by environmental variables which are highly spatially correlated. The NER curve (dashed blue line in Fig. 2b) fits well with the background noise, and al-

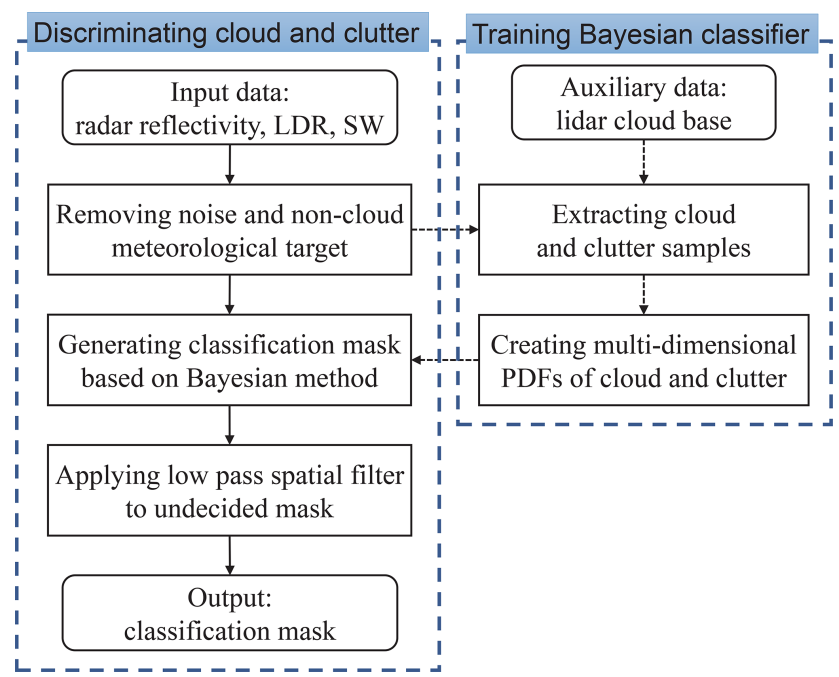

Figure 1. Schematic flow diagram for cloud and clutter discrimination. The right panel (connected by dashed arrows) is only executed once to train the Bayesian classifier.

most all the background noise is removed (Fig. 2c). Additionally, the slanted cloud boundary around $4.5 \mathrm{~km}$, the fluctuant cloud boundary that may be caused by gravity waves around $6.4 \mathrm{~km}$, and the broken thin cirrus boundary around $9.2 \mathrm{~km}$ are all kept (Fig. 2a and c). It is obvious that the clutter reflectivity is not necessarily lower than the cloud reflectivity (Fig. 2b). A single threshold of reflectivity cannot adequately separate clouds from clutter, and therefore multi-dimensional PDFs are needed to describe their differences.

The non-cloud meteorological targets in the low-level atmosphere, such as precipitation and melting layer, usually have different features from cloud droplets. If we put them into the cloud category, it would affect the accuracy of the created PDFs to characterize clouds and clutter. Thus, these non-cloud meteorological targets need to be removed before establishing the multi-dimensional PDFs. Raindrops are normally larger than cloud droplets and have fast fall velocity; thus, radar reflectivity and vertical velocity can be used to identify precipitation (Shupe, 2007). In some cases, the radar-measured velocity may be erroneously aliased (Kollias et al., 2007b; Zheng et al., 2017) when the naturally occurring velocity is larger than the maximum unambiguous velocity ( $V_{\max }, \pm 10.38 \mathrm{~m} \mathrm{~s}^{-1}$ for KAZR at SACOL), as shown in Fig. 3. From this heavy precipitation event, one can see that the radar reflectivity is attenuated above $3 \mathrm{~km}$ (Fig. 3a). The velocity aliasing happens at the lower level of atmosphere, where radar-measured velocity suddenly reverses from large downwards to large upwards (dark red area in Fig. $3 \mathrm{~b}$ and blue dots near the right gray line in Fig. 3d). The absolute value of the gate-to-gate velocity difference is used to check if velocity is aliased. For aliased velocity, that is when absolute velocity difference exceeds $1.5 \times V_{\max }$, $2 \times V_{\max }$ is subtracted from (or added to) the aliased veloc- 
(a)

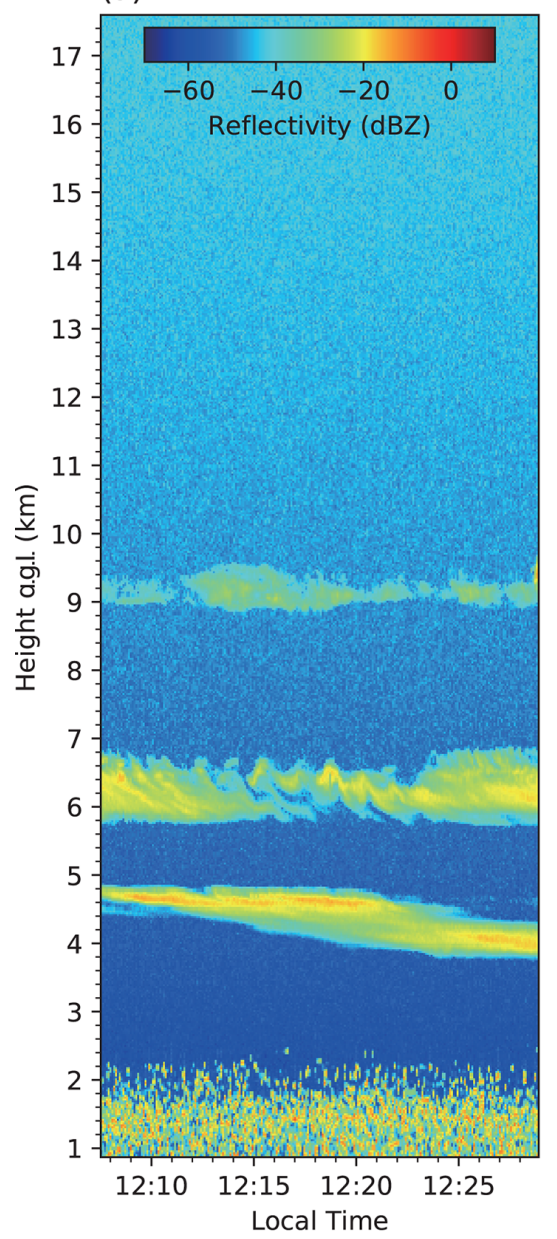

(b)

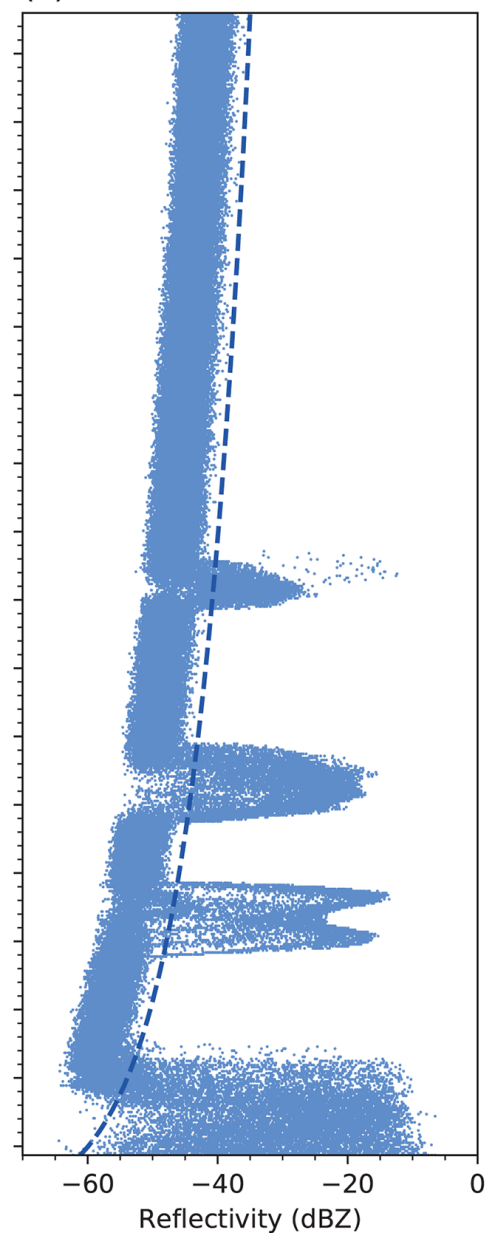

(c)

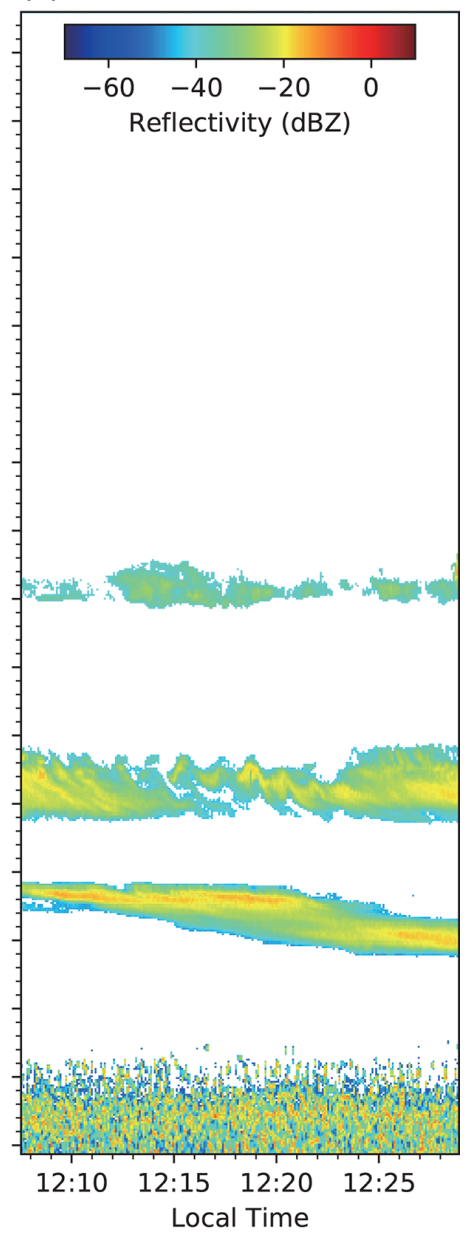

Figure 2. (a) Raw reflectivity and (c) noise-removed reflectivity from 12:08 to 12:29 LT on 28 May 2014. (b) The 300 reflectivity profiles of the same duration; the dashed blue line is noise-equivalent reflectivity curve.

ity if the velocity difference is positive (or negative) (Johnson et al., 2017; Sokol et al., 2018). The adjusted velocity is shown in Fig. 3c, where the upwards velocity at the lower level of atmosphere is de-aliased to downwards (smooth blue region in Fig. 3c and orange dots in Fig. 3d). The de-aliased velocity and reflectivity are then averaged over $1 \mathrm{~min}$ to reduce the effect of wind drift. These range bins with averaged reflectivity greater than $10 \mathrm{dBZ}$ and averaged velocity lower than $-3 \mathrm{~m} \mathrm{~s}^{-1}$ are identified as precipitation (Chandra et al., 2015). However, the drizzle with smaller sizes and lower velocity (Kollias et al., 2011; O'Connor et al., 2005) may not be identified by the above method. Thus, the radar echoes that below the lidar-detected cloud base, while still being connected to the cloud, are marked as drizzle (Wu et al., 2015; Yang et al., 2018) and removed from the training data.

Water-coated ice particles inside the melting layer are largely non-spherical; therefore, they have high LDR values, similar to insects (Brandes and Ikeda, 2004; Islam et al., 2012). This can be seen in Fig. 4c. The melting layer around
$2.8 \mathrm{~km}$ has relatively higher LDRs than the precipitation below and the ice particles above. Clutter near the surface before the precipitation reaches the surface at about 20:30 LT has similar high LDR values. Clutter layer can appear as high as $3 \mathrm{kma.g.l}$. during daytime in the warm season at the SACOL site, which is close to or even higher than melting layer height. In order to avoid wrongly identifying the melting layer with high LDR as clutter, the melting layer is recognized by analyzing the gradient of reflectivity and velocity that has a large value associated with the melting layer (Baldini and Gorgucci, 2006; Matrosov et al., 2007; Perry et al., 2017). The peak of $\mid$ reflectivity $^{\prime}|\times|$ velocity' $\mid$ (Fig. 4e) is located as the middle of the melting layer for each identified precipitation profile; then the height of maximum $\left(\mid \text { reflectivity }^{\prime}|\times| \text { velocity } \mid\right)^{\prime \prime}$ up to $500 \mathrm{~m}$ above (below) the peak is defined as the top (bottom) of melting layer as shown in Fig. 4e with red dots (Devisetty et al., 2019; Khanal et al., 2019). The identified melting layer and precipitation are plotted in Fig. $4 \mathrm{a}-\mathrm{c}$ as black dots and the slashed shading area. 
(a)

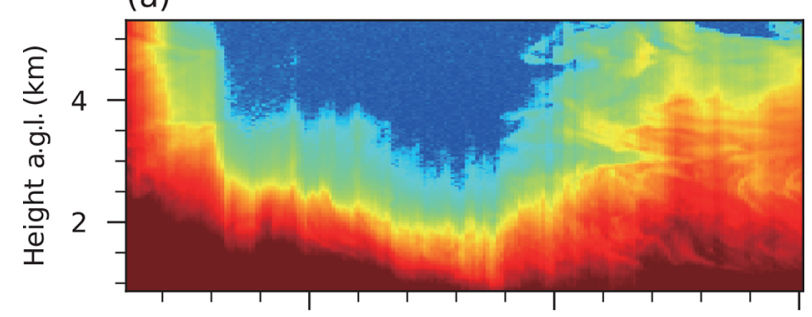

(b)

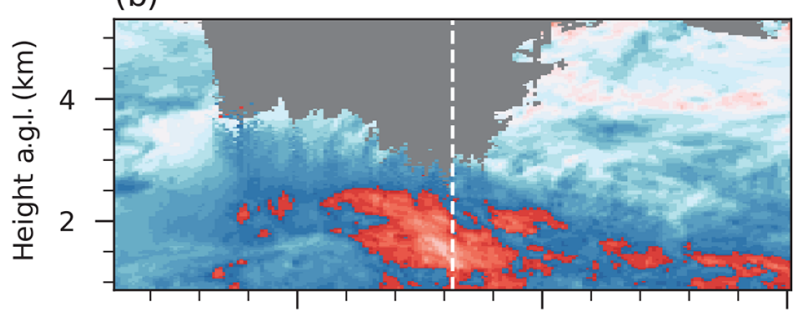

(c)

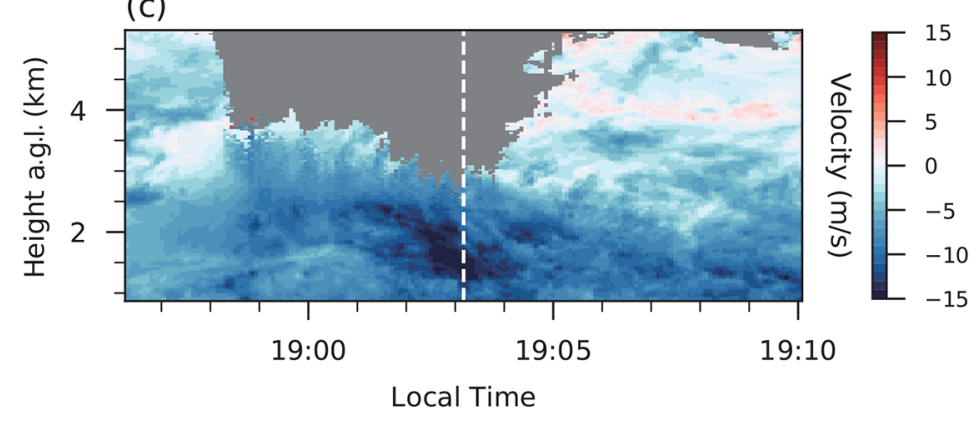

(d)
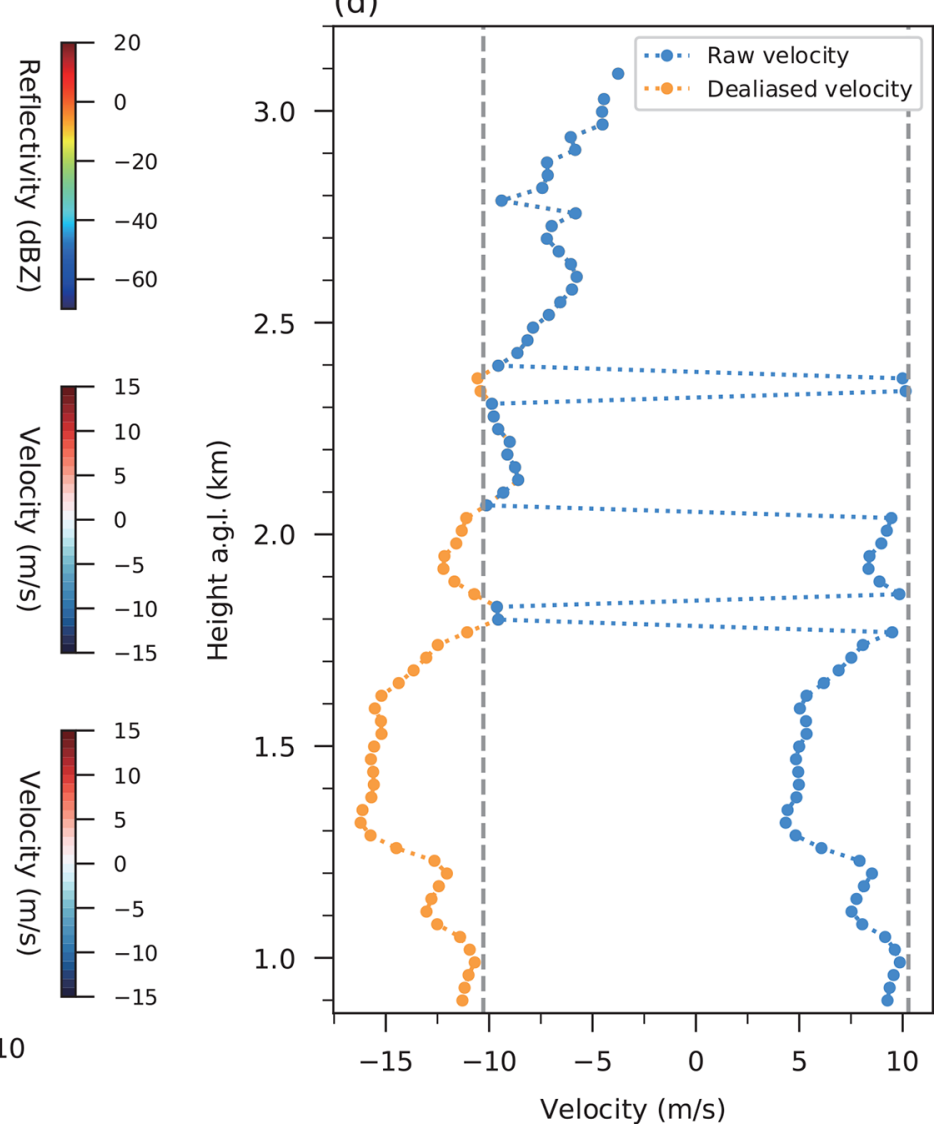

Figure 3. (a) Reflectivity, (b) radar-measured Doppler velocity, and (c) de-aliased velocity from 18:56 to 19:10 LT on 30 August 2013. (d) Raw and de-aliased velocity profile of the dashed white line in the left panels; the dashed gray line is the maximum unambiguous velocity $\left( \pm 10.38 \mathrm{~m} \mathrm{~s}^{-1}\right.$ for SACOL KAZR). Positive velocity represents upwards velocity.

\subsection{Creating multi-dimensional PDFs}

To capture the differences between clouds and clutter as accurately as possible, we need to choose the appropriate discriminants before creating the PDFs for both. From a statistical point of view, the description of differences in higherdimensional space is generally more complete than in lowerdimensional space. Increasing the number of discriminants could decrease the overlapping region of the two PDFs, thereby reducing the fraction of ambiguous classifications (Liu et al., 2004). However, only when the added discriminant is largely independent of the other used, can it improve the classification significantly (Liu et al., 2009). After carefully examining all radar variables for many specific clutter and cloud cases, we chose radar reflectivity, LDR, and SW along with their time-height and seasonal dependence as discriminants. LDR is chosen because it has distinct distributions for clouds and clutter due to their shape difference (cloud droplets are largely spherical, while clutter is nonspherical). Insects' number density and sizes make them often generate low radar reflectivity, which has a similar range with strati and broken cumuli (Luke et al., 2008) but is com- monly higher in the warm seasons when they swarm (Abrol, 2015). The seasonal dependence of radar reflectivity is considered as a factor to build the PDFs. Clutter also generally has lower SW and lower vertical velocity because insects may actively oppose environmental vertical motion and control their own flying behavior, while cloud particles are more vulnerable to small-scale local turbulence and entrainment processes (Geerts and Miao, 2005). Yet after checking both variables, we found that distributions of SW for clouds and clutter are more discrepant than that of vertical velocity; thus, SW is used to build the PDFs rather than using vertical velocity directly. One distinctive characteristic of insects that differs from other fixed clutter is that their behavior is influenced by many natural factors (Chapman et al., 2015; Johnson et al., 2016; Thomas et al., 2003). For example, insects' number density has a high correlation with surface temperature (Luke et al., 2008); thus, the maximum height and radar echo intensity of insects have strong diurnal cycles (Hubbert et al., 2018; Wood et al., 2009). The time and height variations of radar echoes are thereby considered in the construction of multi-dimensional PDFs. 
(a)

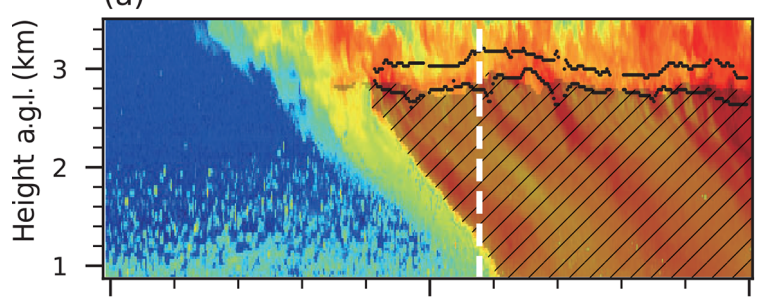

(b)

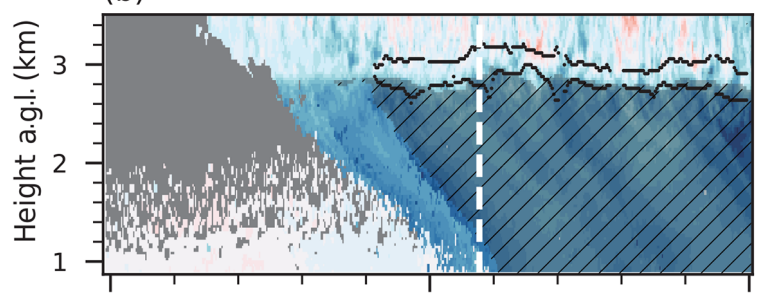

(c)

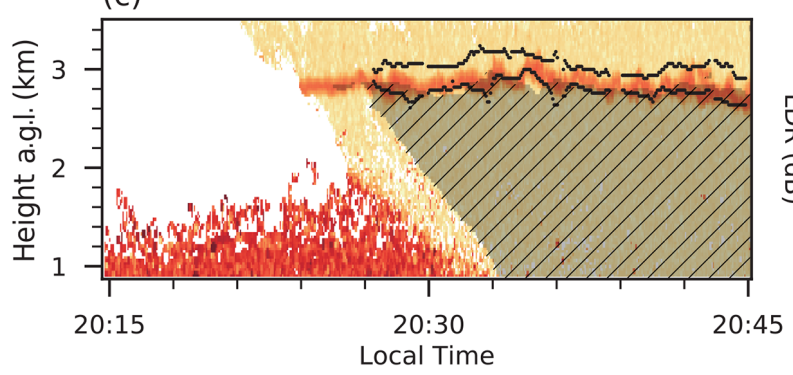

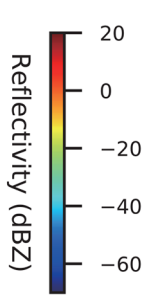
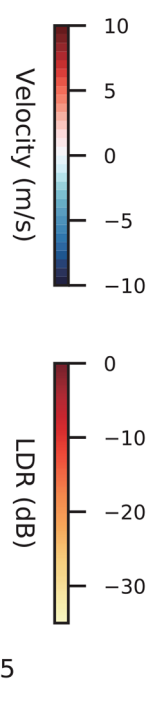

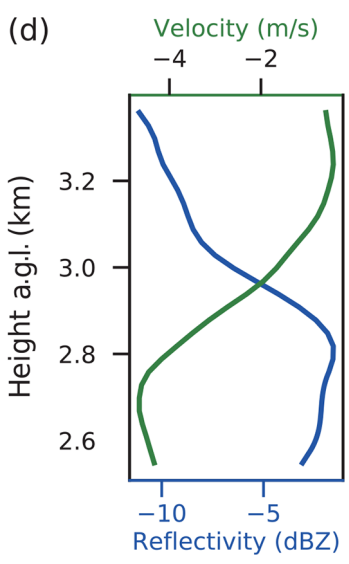

(e)

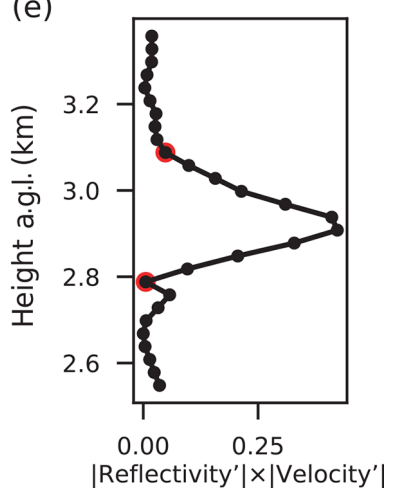

Figure 4. (a) Reflectivity, (b) velocity, and (c) LDR from 20:15 to 20:45 LT on 10 August 2013. (d) Reflectivity and velocity, and (e) $\mid$ reflectivity $^{\prime}|\times|$ velocity $\mid$ profile of the dashed white line in panels (a-b). Black dots and the slashed shading area in panels (a-c) are the identified melting layer and precipitation. Red dots in panel (e) are the identified bottom and top of the melting layer.

Once the discriminant factors are selected, the cloud and clutter samples need to be extracted for building the multidimensional PDFs. The radar echoes above the lidar cloud base height after removing noise and non-cloud meteorological targets are considered to be clouds; otherwise, they are clutter. Based on the lidar auxiliary data, all the radar echoes below $3.6 \mathrm{~km}$ from August 2014 to July 2015 are separated into cloud or clutter samples. Figures 5 and 6 show the multidimensional PDFs for different local times and heights for the warm and cold seasons, respectively, which is calculated as the number of samples in each discriminant range for each class (clouds or clutter), divided by the total number of samples in each discriminant range for all classes. After examining 1-year data, it is found that $3.6 \mathrm{kma}$.g.l. is the highest level that clutter can reach at the SACOL site. As expected, clutter tends to have lower reflectivity (lower density), larger LDR (non-spherical shape) and lower SW (less turbulent motion) compared with clouds (Figs. 5 and 6). Insect activities are largely influenced by temperature; thus, the clutter appears mostly during daytime and its height has an obvious diurnal cycle. It is also notable that there is no clutter above $2.7 \mathrm{~km}$ during nighttime (Figs. $5 \mathrm{c} 1, \mathrm{~d} 1$ and $6 \mathrm{c} 1, \mathrm{~d} 1$ ). The three radar variables for clouds and clutter still have con- trasting distributions during the cold season. Nevertheless, both clouds and clutter occur less frequently compared to the warm season (Zhu et al., 2017). Note that some overlapping regions of cloud and clutter PDFs still occur (e.g., Fig. 5b3). However, the multi-dimensional PDFs made the ambiguity area much smaller compared with the results by only using a single discriminant. The significant differences between clutter and cloud PDFs (Figs. 5 and 6) can be used to adequately separate them more accurately.

\subsection{Generating classification mask based on Bayesian method}

The obtained multi-dimensional PDFs are then used to train the optimal Bayesian classifier to separate clouds and clutter for any observed discriminants $\left(\boldsymbol{X}^{\mathrm{O}}\right)$. According to Bayesian method, the probability of a radar range gate with discriminants $\boldsymbol{X}=\boldsymbol{X}^{\mathrm{O}}=$ Reflectivity $^{\mathrm{O}}, \mathrm{LDR}^{\mathrm{O}}, \mathrm{SW}^{\mathrm{O}}$, time $^{\mathrm{O}}$, height $^{\mathrm{O}}$, season ${ }^{\mathrm{O}}$ being class $C_{i},(i \in$ [cloud, clutter] $)$ can be estimated as

$p\left(C_{i} \mid \boldsymbol{X}=\boldsymbol{X}^{\mathrm{O}}\right)=\frac{p\left(\boldsymbol{X}=\boldsymbol{X}^{\mathrm{O}} \mid C_{i}\right) p\left(C_{i}\right)}{p\left(\boldsymbol{X}=\boldsymbol{X}^{\mathrm{O}}\right)}$, 
(a1) LT 06:00-12:00, height $2.7-3.6 \mathrm{~km}$

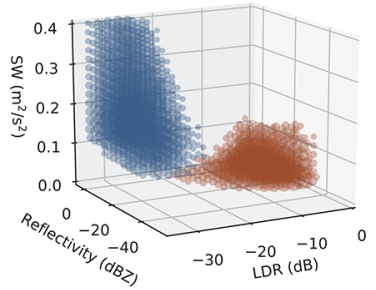

(a2) LT 06:00-12:00, height 1.8-2.7 km

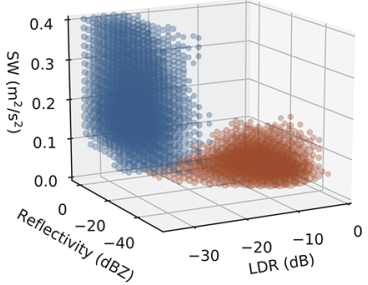

(a3) LT 06:00-12:00, height below $1.8 \mathrm{~km}$

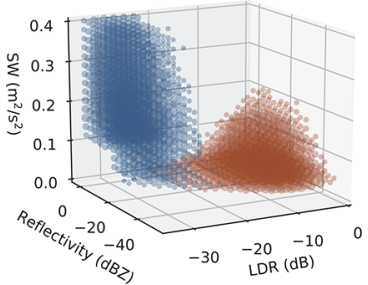

(b1) LT 12:00-18:00, height 2.7-3.6 km

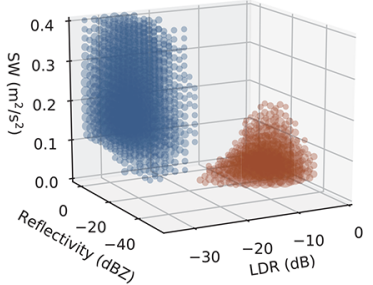

(b2) LT 12:00-18:00, height 1.8-2.7 km

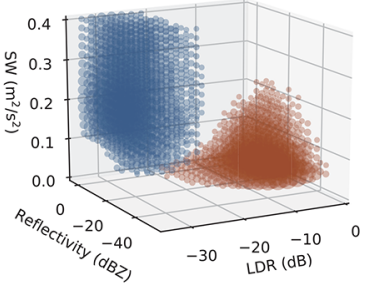

(b3) LT 12:00-18:00, height below $1.8 \mathrm{~km}$

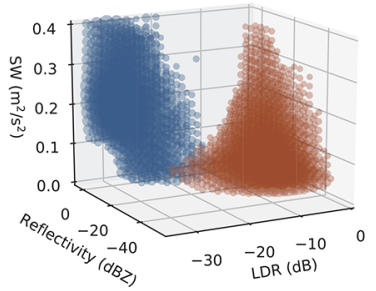

(c1) LT 18:00-24:00, height 2.7-3.6 km

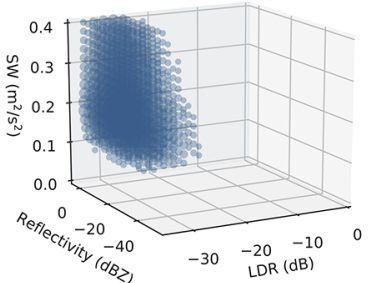

(c2) LT 18:00-24:00, height 1.8-2.7 km

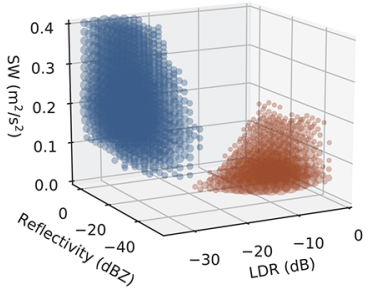

(c3) LT 18:00-24:00, height below $1.8 \mathrm{~km}$

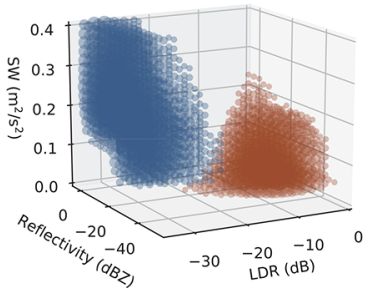

(d1) LT 00:00-06:00, height $2.7-3.6 \mathrm{~km}$

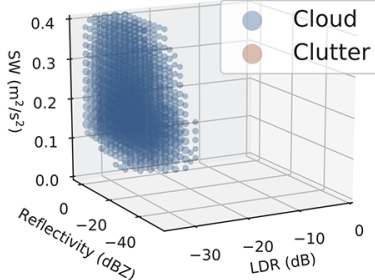

(d2) LT 00:00-06:00, height 1.8-2.7 km

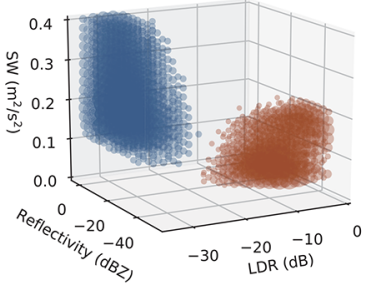

(d3) LT 00:00-06:00, height below $1.8 \mathrm{~km}$

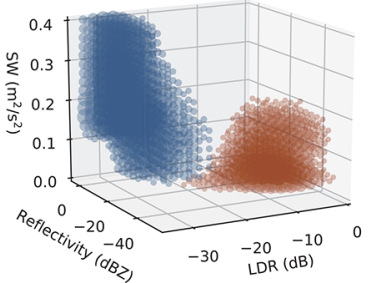

Figure 5. The multi-dimensional PDFs of clutter (brown dots) and cloud droplets (blue dots) at 06:00-12:00 (column a), 12:00-18:00 (column b), 18:00-24:00 (column c), and 00:00-06:00 LT (column d), and height below 1.8 km (row 3), 1.8-2.7 km (row 2) and 2.7-3.6 km (row 1) in the warm season (April to September). The size of dots represents the value of probability density.

where the priori probabilities are assumed to be equal for all classes (Golbon-Haghighi et al., 2016; Ma et al., $2019)$, which means $p\left(C_{\text {cloud }}\right)=p\left(C_{\text {clutter }}\right)=1 / 2$. Furthermore, $p\left(\boldsymbol{X}=\boldsymbol{X}^{\mathrm{O}}\right)$ is the same for all classes; hence, Eq. (1) can be rewritten as

$p\left(C_{i} \mid \boldsymbol{X}=\boldsymbol{X}^{\mathrm{O}}\right)=K p\left(\boldsymbol{X}=\boldsymbol{X}^{\mathrm{O}} \mid C_{i}\right)$,

where $K$ is constant for all classes

$K=\frac{1}{2 p\left(X=X^{\mathrm{O}}\right)}$

and $p\left(\boldsymbol{X}=\boldsymbol{X}^{\mathrm{O}} \mid C_{i}\right)$ is the conditional probability of discriminants being $\boldsymbol{X}^{\mathrm{O}}$ for each class, which has been derived from 1-year training data as described in Sect. 3.2.

For any given observation of discriminants, the posterior probability for each class $p\left(C_{i} \mid \boldsymbol{X}=\boldsymbol{X}^{\mathrm{O}}\right)$ is estimated accordingly and compared to decide its category. The radar range gate belongs to clouds only when $p\left(C_{\text {cloud }} \mid \boldsymbol{X}=\right.$ $\left.\boldsymbol{X}^{\mathrm{O}}\right)$ is larger than $p\left(C_{\text {clutter }} \mid \boldsymbol{X}=\boldsymbol{X}^{\mathrm{O}}\right)$. And vice versa, if $p\left(C_{\text {clutter }} \mid \boldsymbol{X}=\boldsymbol{X}^{\mathrm{O}}\right)$ is larger than $p\left(C_{\text {cloud }} \mid \boldsymbol{X}=\boldsymbol{X}^{\mathrm{O}}\right)$, it is considered to be a clutter gate.

\subsection{Applying a low-pass spatial filter to undecided mask}

The Bayesian classifier is able to separate clouds and clutter in most cases when all the radar discriminants as described in Sect. 3.2 and 3.3 are offered. Figure 7 shows such a case from 05:00 to 22:00 LT on 24 September 2013. Unsurprisingly, these radar range bins with low reflectivity (Fig. 7a), high LDR (Fig. 7c), and low SW (Fig. 7d) are considered more likely to be clutter rather than clouds (Fig. 7e, f and g), while high reflectivity, low LDR, and high SW have higher probability to be clouds (Fig. 7a-g). When the individual three radar variables disagree on the classification, for example, this clutter from 12:00 to 16:00 LT near the surface with high reflectivity and high SW (likely to be clouds) and high LDR (also likely to be clutter), the Bayesian classifier can still correctly separate them, as shown in Fig. 7g. However, the cloud radar may not always provide valid observations. For example, LDR can only be computed when both co- and crosspolarized reflectivities are available. Figure $7 \mathrm{a}$ and $\mathrm{b}$ show the reflectivities of co- and the cross-polarized channels, respectively. There are some range gates where co-polarized reflectivity detects signal (cloud or clutter), while no signal 
(a1) LT 06:00-12:00, height 2.7-3.6 km

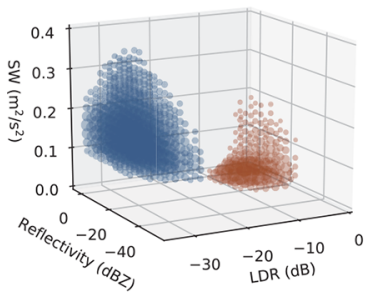

(a2) LT 06:00-12:00, height 1.8-2.7 km

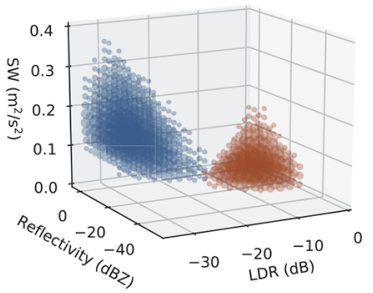

(a3) LT 06:00-12:00, height below $1.8 \mathrm{~km}$

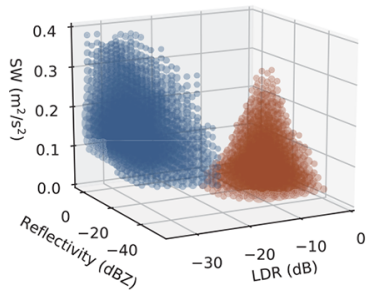

(b1) LT 12:00-18:00, height 2.7-3.6 km

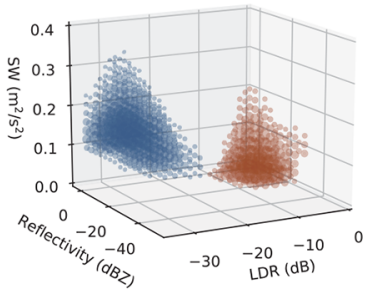

(b2) LT 12:00-18:00, height 1.8-2.7 km

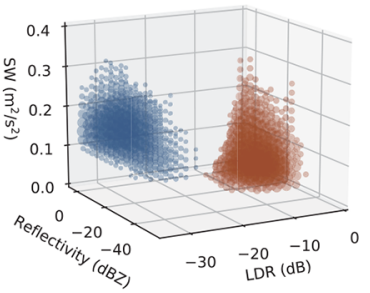

(b3) LT 12:00-18:00, height below $1.8 \mathrm{~km}$

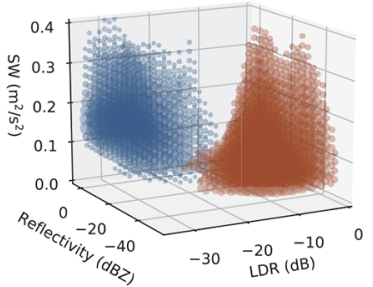

(c1) LT 18:00-24:00, height 2.7-3.6 km

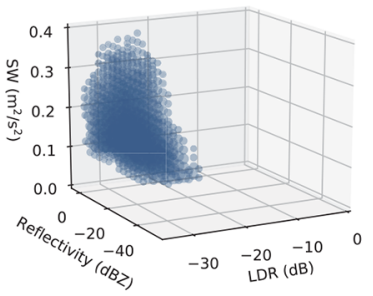

(c2) LT 18:00-24:00, height 1.8-2.7 km

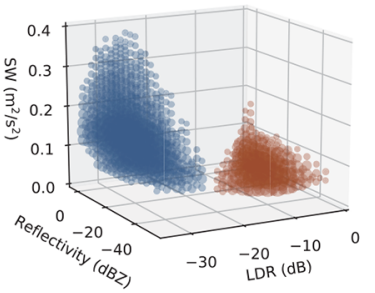

(c3) LT 18:00-24:00, height below $1.8 \mathrm{~km}$

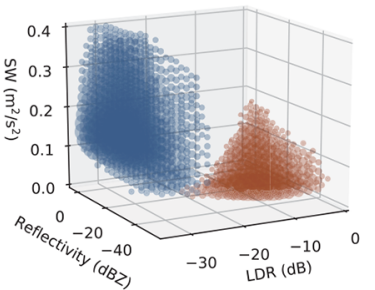

(d1) LT 00:00-06:00, height 2.7-3.6 km

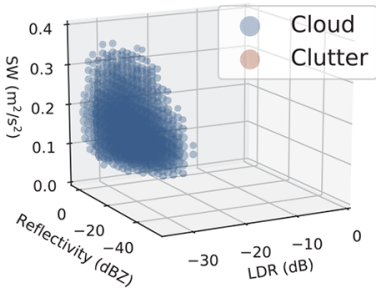

(d2) LT 00:00-06:00, height 1.8-2.7 km

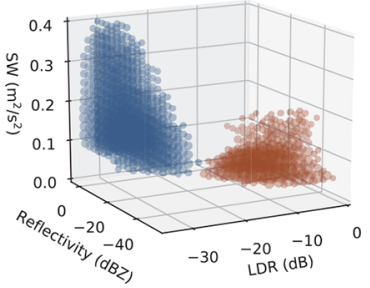

(d3) LT 00:00-06:00, height below $1.8 \mathrm{~km}$

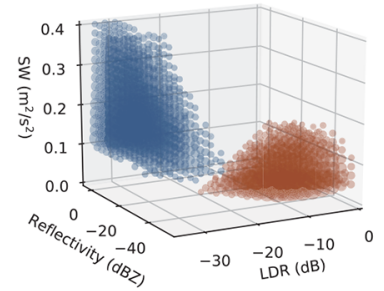

Figure 6. Same as Fig. 5 but for the cold season (October to March).

is detected in the cross-polarized channel, which causes the missing LDR in these radar range gates (e.g., the rightmost range bins above the lidar cloud base and some bins scattering near-surface in Fig. 7c). Without the LDR input data, the Bayesian classifier fails to work (green dots in Fig. 7g), because no conditional probability was established for an incomplete $\boldsymbol{X}^{\mathrm{O}}$. Mathematically, there are several approaches to deal with missing data for the Bayesian method, such as assuming a distribution of them (Linero and Daniels, 2018). However, in practice, we find it is uneconomical to solve such an issue. Rather, we utilize the spatial correlation difference between clouds and clutter to process the Bayesian undecided classifications, which is more effective and simpler. As mentioned earlier, cloud droplets are highly correlated in time and space, while clutter does not have the same feature. For those radar bins that cannot be identified as clouds or clutter from the probability estimate, we use their neighboring range gates to provide information to help make the final decision. A spatial filter with five range bins respecting to height $(150 \mathrm{~m})$ and five range bins concerning time (21.4 s), which is centered at each undecided classification bin, is employed here (Hu et al., 2020; Marchand et al., 2008). Following Ge et al. (2017), if the number of cloud range bins in the box is less than 13, this range bin is considered to be clutter; otherwise, it will be marked as a cloud bin. The fi- nal classification mask result is shown in Fig. 7h. Comparing with lidar observation on the same day, the undecided range bins are correctly categorized into clutter (green dots turned to brown) and clouds (green dots turned to blue above lidar cloud base) after applying the low-pass spatial filter. It is clear from Fig. 7h that clutter layer height has an apparent diurnal cycle and the insects' number density is much stronger in the early afternoon near the surface (patchy high reflectivity rather than dotted low reflectivity). This is why time and height are also chosen as the discriminants.

\section{Result}

\subsection{Case study}

We apply the identification algorithm to a whole year of radar data to discriminate low-level clouds and clutter. The results are compared with the simultaneous lidar cloud base to demonstrate the performance of the algorithm.

Figure 8 shows a case of broken cumulus from 16:27 to 17:30 LT on 15 April 2014. During this period, a substantial presence of insects is observed below the broken cumulus. The top of the insect layer is around $1.6 \mathrm{~km}$, where there is also the cloud base height detected by lidar and our algorithm (Fig. 8d). From the radar reflectivity image in 

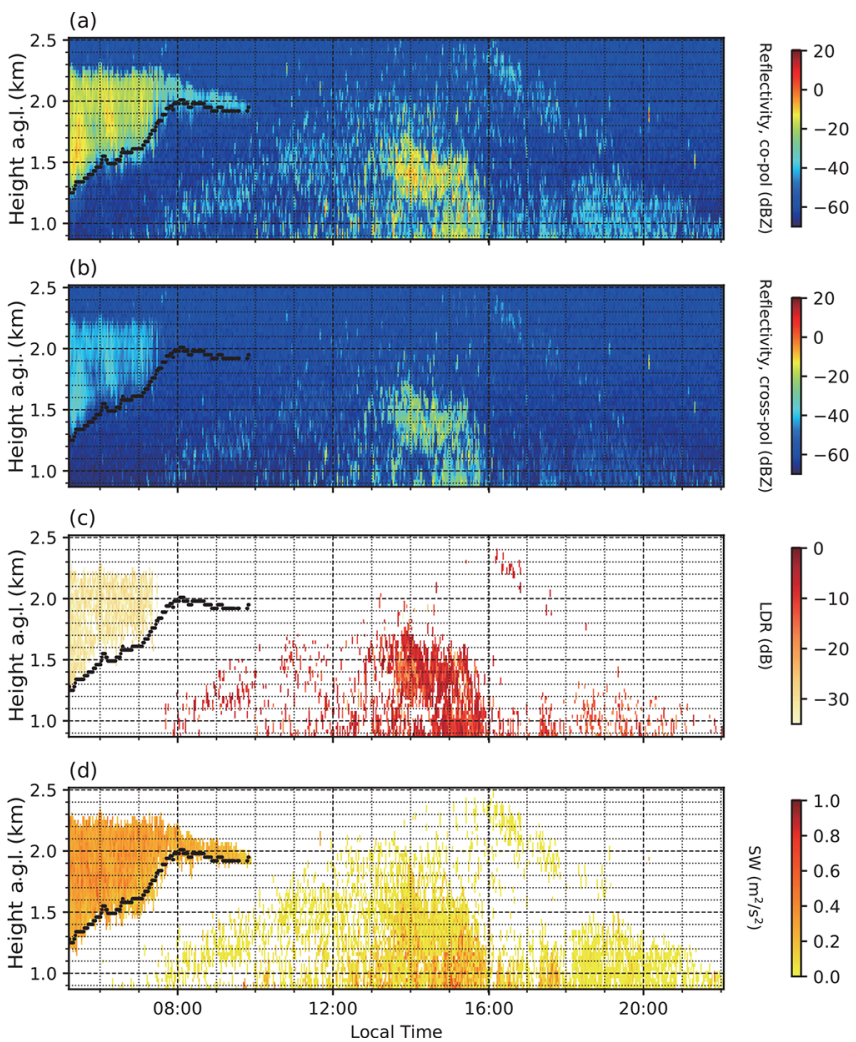

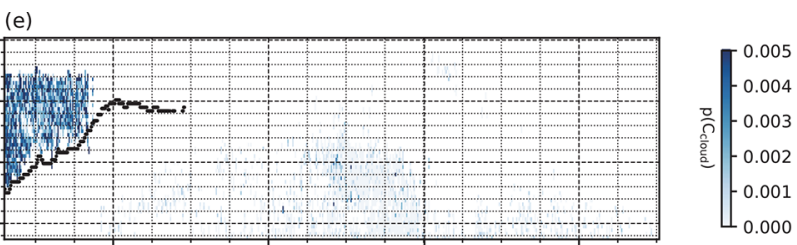

(f)
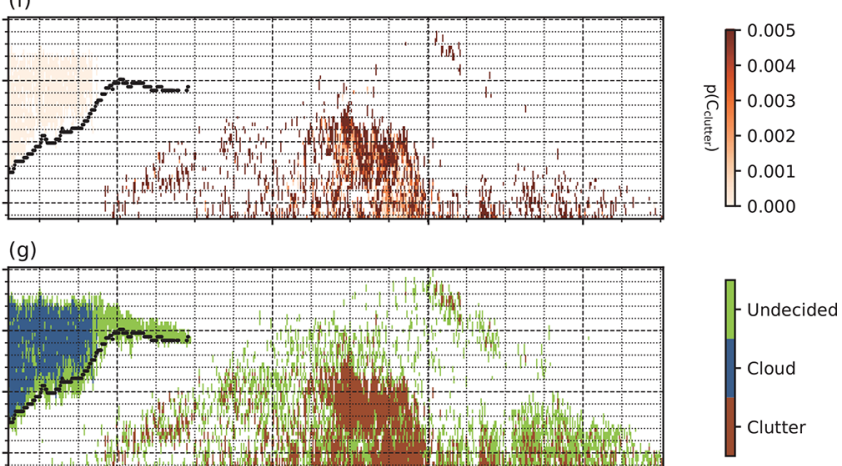

(h)
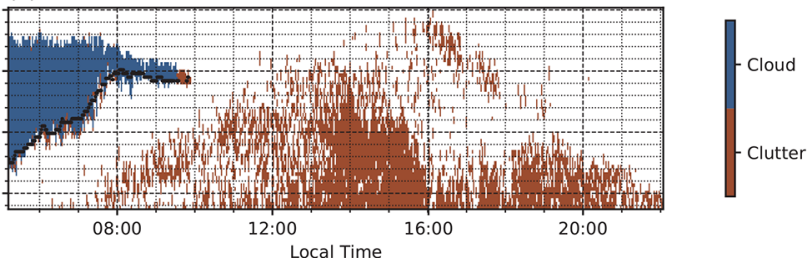

Figure 7. (a) Reflectivity of co-polarized (co-pol), (b) reflectivity of cross-polarized (cross-pol), (c) LDR, (d) SW, (e) estimated probability of cloud, (f) estimated probability of clutter, (g) classification mask using the Bayesian method, and (h) classification mask after the spatial filter from 05:00 to 22:00 LT on 24 September 2013. The black dots represent lidar-detected cloud base height.

Fig. 8a, the cloud droplets begin to dissipate due to entrainment (Chernykh et al., 2001; Pinsky and Khain, 2019) and have similar reflectivity values as clutter (around $-50 \mathrm{dBZ}$ ) around the cloud base. As shown in Fig. 8b, clutter has the LDRs mostly greater than $-15 \mathrm{~dB}$ but clouds have relatively smaller LDR values. The high SW above the cloud base (more than $0.4 \mathrm{~m}^{2} \mathrm{~s}^{-2}$ ) indicates strong turbulence inside the cumulus. Combining all these radar variables together, our clutter identification algorithm shows a great agreement with lidar detection (Fig. 8d).

Figure 9 shows a case of stratus clouds embedded in insect layers. The reflectivity inside clouds is similar to the clutter reflectivity (between -40 to $-20 \mathrm{dBZ}$ ) but is distributed more homogeneously in time and space (Fig. 9a). Note that for these flat clouds, Kalapureddy et al. (2018) used the standard deviation of reflectivity to remove clutter. However, this method causes some false positives (clouds are wrongly identified as clutter) around fuzzy cloud edges. The stratus cloud is typically more featureless than the cumulus (Fig. 8) due to the absence of active convective elements (Harrison et al., 2017), and it has lower SW values which may fall within the same range as clutter (below $0.4 \mathrm{~m}^{2} \mathrm{~s}^{-2}$; Fig. 9c). Thus, in this case, the LDR (Fig. 9b) and spatial filter in our method made the major contribution to separate them.
Figure 10 shows a case of precipitating stratocumulus. The drizzle droplets that fall from the cloud base are kept as clouds (Fig. 10d), since they have relatively small falling velocity and reflectivity, and cannot be recognized as precipitation by the algorithm. The edges between clutter and drizzle are blurry in radar reflectivity and SW (Fig. 10a and c). Under this circumstance, the algorithm identifies the clutter near the surface with large LDR (larger than $-15 \mathrm{~dB}$ ) but keeps the drizzle as hydrometeors with a low-pass filter since they are temporally and spatially correlated (Fig. 10b). Note that although the bottom of identified hydrometeors is coincidental with the top height of the clutter layer (Fig. 10d), it does not mean that the drizzle droplets "suddenly" all evaporate when they fall into the insect layer. The drizzle may still fall toward the ground; however, the signals are much smaller than that from the insect layer. In other words, the clutter mask does not necessarily mean only clutter can be in this range bin; rather, the backscattered power is largely dominated by insects.

Figure 11 shows a case of broken cumulus and shallow convective clouds under stratus. One can see a few thin clouds (less than $300 \mathrm{~m}$ ) below $1.5 \mathrm{~km}$ a.g.l. during 04:55 to 05:15 LT and some broken cumulus from 04:30 to 04:50 LT like the case shown in Fig. 8 but with lower cloud top and 
(a)

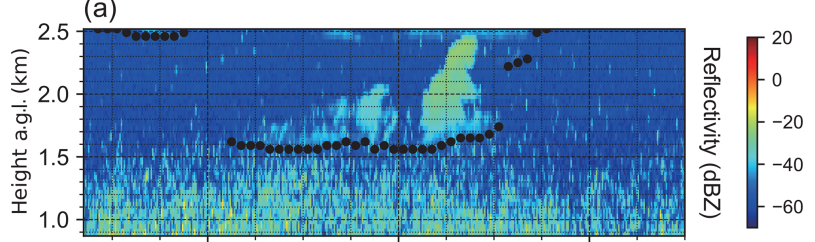

(b)
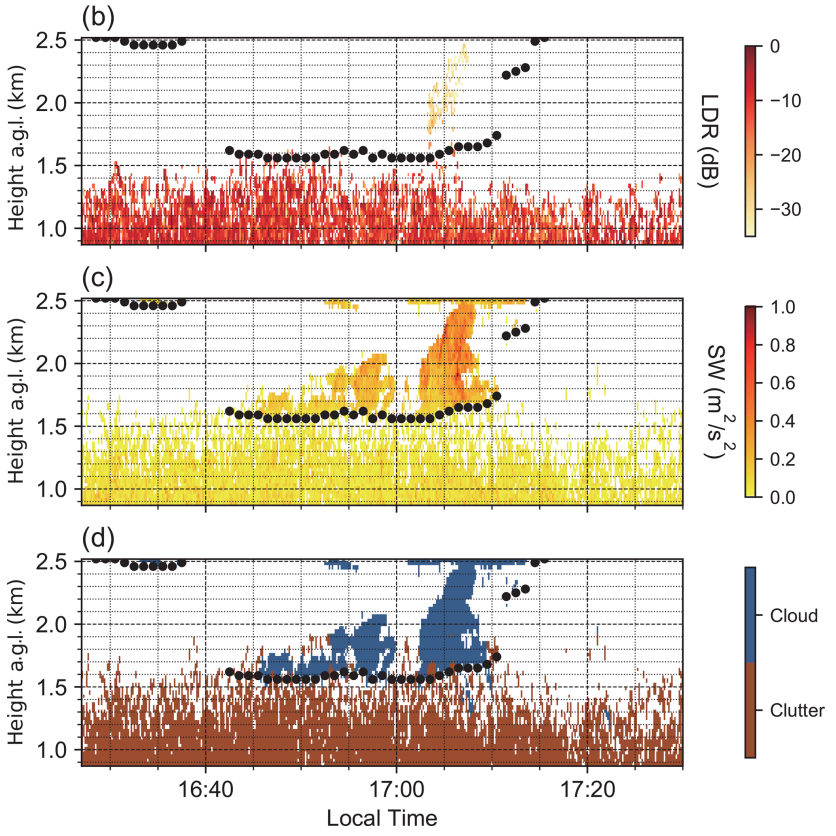

Figure 8. (a) Reflectivity, (b) LDR, (c) SW, and (d) classification mask from 16:27 to 17:31 LT on 15 April 2014. The black dots are lidar-detected cloud base.

base heights ("more deeply buried" in the clutter layer). There may be many insets in the cloud, causing the large radar-observed LDR, e.g., from 04:30 to 04:40 LT (greater than $-15 \mathrm{~dB}$; Fig. $11 \mathrm{~b}$ ); therefore, these range gates are classified as clutter by our algorithm (Fig. 11d). The clouds, which are less affected by insects from 04:40 to 04:50 LT (lower LDR than $-15 \mathrm{~dB}$ and higher SW than $0.4 \mathrm{~m}^{2} \mathrm{~s}^{-2}$ ), are identified as clouds without doubt. Note the occurrence of interlaced blocky appearance of classification masks around 04:40 LT (Fig. 11d). There are only few available LDR range gates there (Fig. 11b), meaning the classification masks are mostly achieved by the spatial filter (Sect. 3.4), which causes some misclassification (e.g., from 04:30 to 04:40 LT) because the spatial correlation of clouds is reduced since they are largely contaminated by clutter. During 04:55 to 05:15 LT, a few broken clouds higher away from the clutter layer are successfully identified by the algorithm, which is in accordance with the MPL lidar detection, indicating the spatial filter does work well when clouds are not adjacent to falsely identified masks. The shallow convective clouds after 05:15 LT are more turbulent ( $\mathrm{SW}$ greater than $0.6 \mathrm{~m}^{2} \mathrm{~s}^{-2}$; Fig. 11c) than these broken cumuli; thus, they are effectively identified as clouds even with a dense clutter layer below.
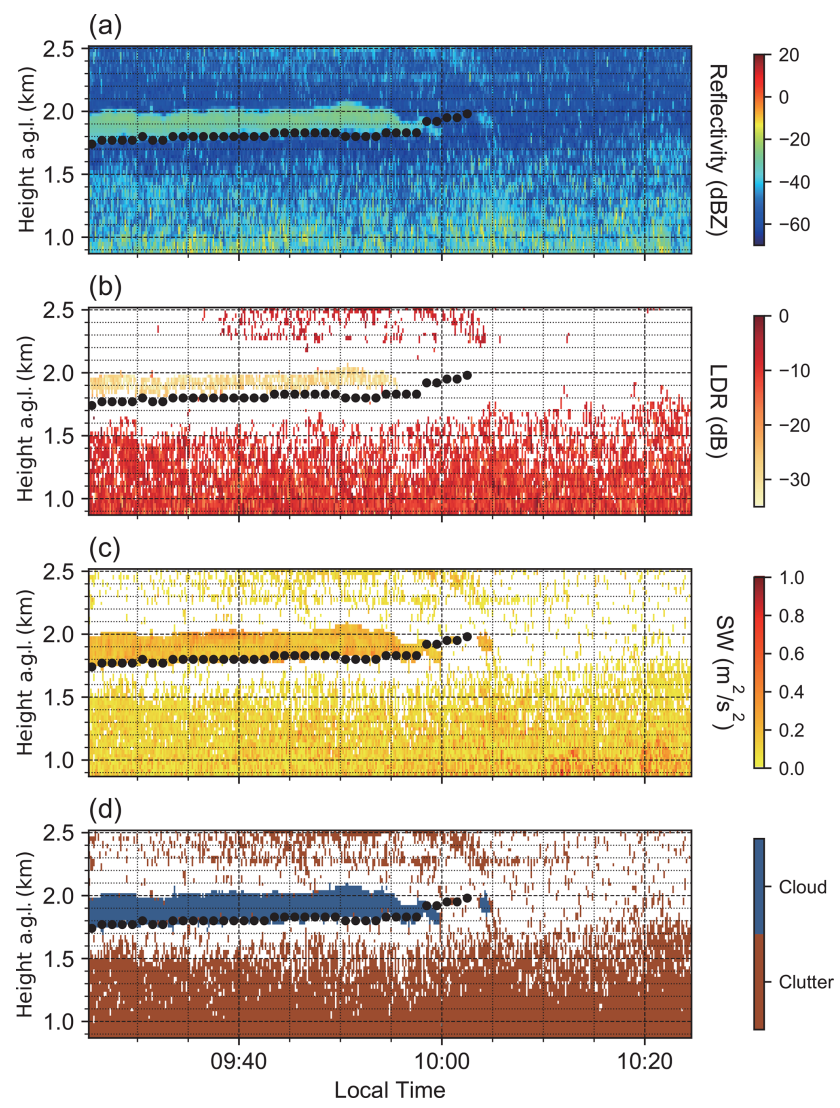

Figure 9. Same as Fig. 8 but for 09:25 to 10:25 LT on 12 October 2013.

We believe the identified cloud masks below lidar cloud base from 05:15 to 05:30 LT are drizzle particles because of the virga reflectivity during that time (Fig. 11a).

Figure 12 shows a case of low-level clouds completely surrounded by intense insects. This is the most difficult case to discriminate, because cloud signals are heavily contaminated by clutter. Figure $12 \mathrm{~d}$ shows that the identified cloud masks correspond well with lidar cloud base during 14:15 to 16:00 LT, due to lower LDR (less than $-15 \mathrm{~dB}$; Fig. 12b) and higher SW (greater than $0.4 \mathrm{~m}^{2} \mathrm{~s}^{-2}$; Fig. 12c) of the cloud particles. However, the algorithm misses some clouds with low SW (around $0.2 \mathrm{~m}^{2} \mathrm{~s}^{-2}$; Fig. 12c) from 16:00 to 16:40 LT. Note that a large number of LDRs are unavailable for this cloud (Fig. 12b) and its structure is loose (Fig. 12a), especially around cloud edges where clutter signals are even stronger than clouds. In this circumstance, the algorithm can only identify a part of the cloud.

Figure 13 shows a case of shallow cumulus near the surface in the cold season. Compared with the earlier cases (Figs. 8-12), the clutter in this case is less organized. There is no dense insect layer gathering near the surface. The different behavior of insects in the warm and cold seasons is why seasonal variation is chosen as a discriminant. The radar reflectivity in the cumulus is more homogenous than that 

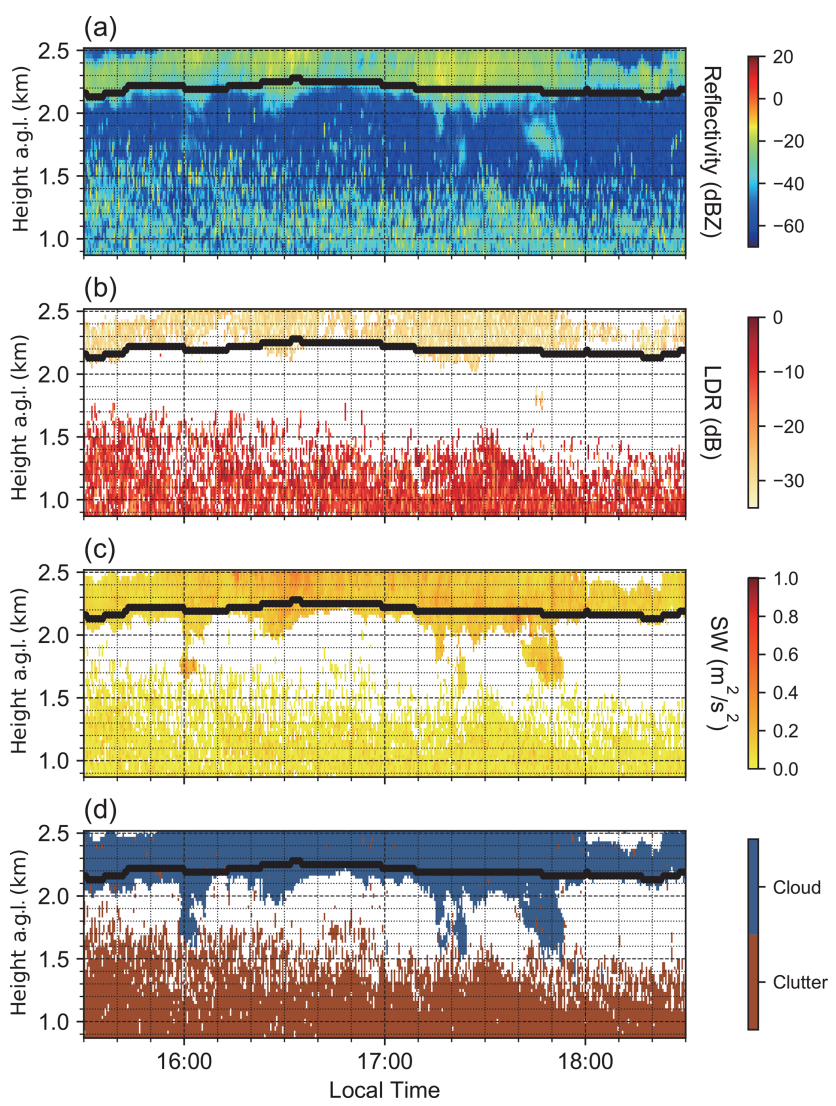

Figure 10. Same as Fig. 8 but from 15:30 to 18:30 LT on 7 July 2014.

from the scattering clutter (Fig. 13a) and can easily be identified even through human eyes. Shallow cumulus clouds have LDR of less than $-20 \mathrm{~dB}$, whereas clutter has higher LDR greater than $-15 \mathrm{~dB}$ (Fig. 13b). Higher SW values (around $0.6 \mathrm{~m}^{2} \mathrm{~s}^{-2}$; Fig. 13c) in the cumulus during 18:00 to 20:30 LT indicate that the cloud droplets are more affected by smallscale local turbulence and entrainment processes. The algorithm can screen out the shallow cumulus in the cold season and filter out the clutter (Fig. 13e).

\subsection{The 1-year evaluation}

To further objectively demonstrate the performance of this algorithm, probability of detection $\left(P_{\mathrm{D}}\right)$ and false alarm rate $\left(P_{\mathrm{FA}}\right)$ are calculated using 1-year data (August 2013 to July 2014) that are defined as

$$
\begin{aligned}
& P_{\mathrm{D}}=\frac{\mathrm{TP}}{\mathrm{TP}+\mathrm{FN}} \\
& P_{\mathrm{FA}}=\frac{\mathrm{FP}}{\mathrm{FP}+\mathrm{TN}},
\end{aligned}
$$

where the number of TP (true positives), TN (true negatives), FP (false positives) and FN (false negatives) is based on our algorithm-identified clutter ("positive" of "negative") vali-
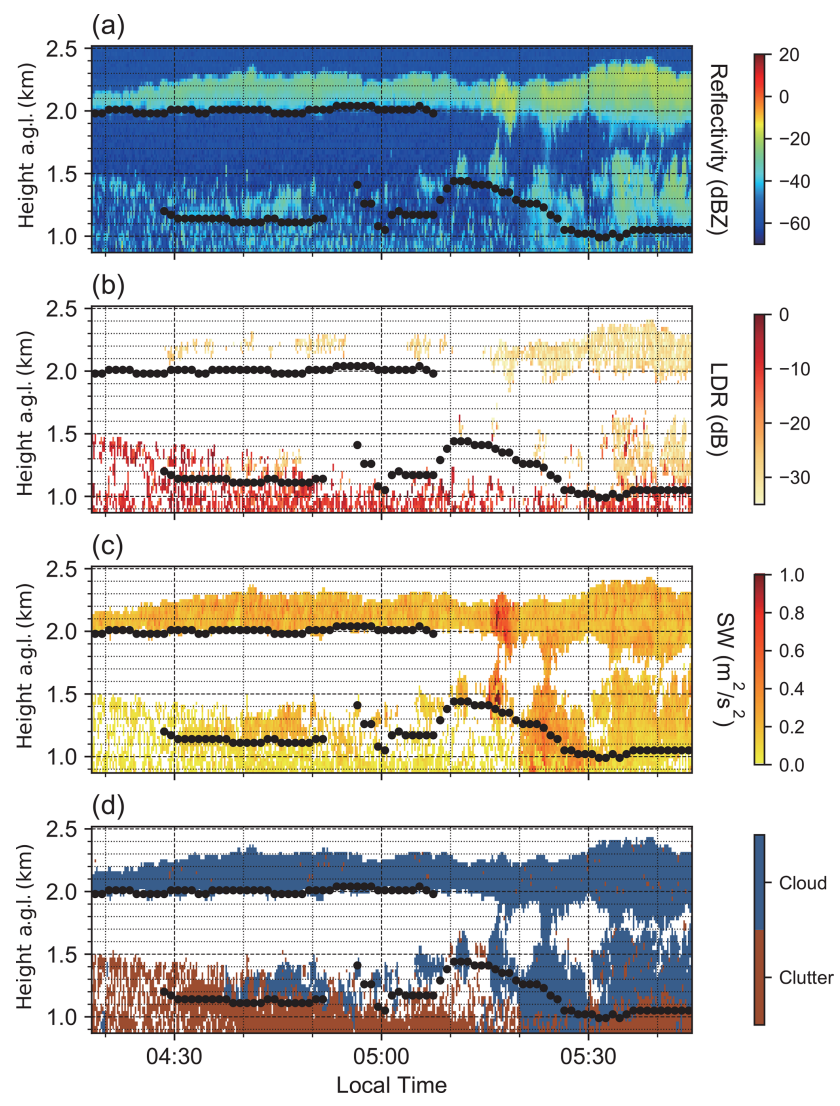

Figure 11. Same as Fig. 8 but for $04: 18$ to $05: 45$ LT on 20 July 2014.

dated by lidar detection ("true" or "false" clutter classification mask). Note that the evaluation is focused on the identified clutter rather than low-level clouds, because lidar power is often attenuated by optically thick low-level water clouds, leading to a significant discrepancy between radar- and lidarmeasured low-level clouds, while the "true" or "false" clutter only relies on lidar cloud base height, which would cause less uncertainty in the assessment.

Figure 14 illustrates the $P_{\mathrm{D}}$ and $P_{\mathrm{FA}}$ as functions of reflectivity (a), LDR (b), SW (c), time (d), and height (e). The $P_{\mathrm{D}}$ (solid lines) is usually above $98 \%$, except when reflectivity is larger than $-10 \mathrm{dBZ}$ (Fig. 14a), LDR lower than $-15 \mathrm{~dB}$ (Fig. 14b), or SW larger than $0.2 \mathrm{~m}^{2} \mathrm{~s}^{-2}$ (Fig. 14c), where clutter has similar properties to clouds, however, which are only small portions of the whole dataset, as shown in Figs. 5 and 6 . So the seasonally and yearly averaged $P_{\mathrm{D}}$ values are all near or above $98 \%$ (Fig. 14f). Similarly, for the cloud with reflectivity lower than $-30 \mathrm{dBZ}$ (Fig. 14a), LDR larger than $-20 \mathrm{~dB}$ (Fig. 14b), and SW lower than $0.1 \mathrm{~m}^{2} \mathrm{~s}^{-2}$ (Fig. 14c), there are chances that clouds are falsely identified as clutter (higher $P_{\mathrm{FA}}$, dashed lines). The $P_{\mathrm{FA}}$ values are below $0.5 \%$ in all seasons (Fig. 14f). Using a single LDR threshold to filter out clutter would induce a sharp increase of $P_{\mathrm{D}}$ from $0 \%$ to $100 \%$ at the threshold point. Very differ- 


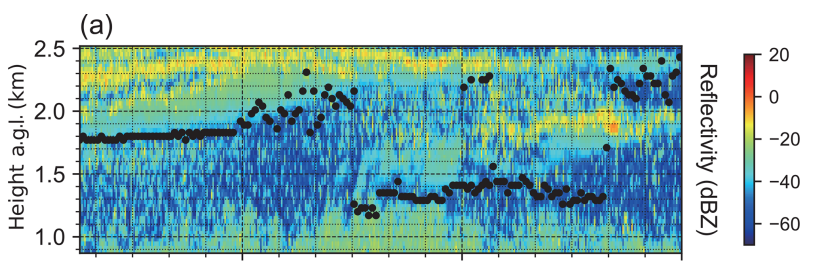

(b)
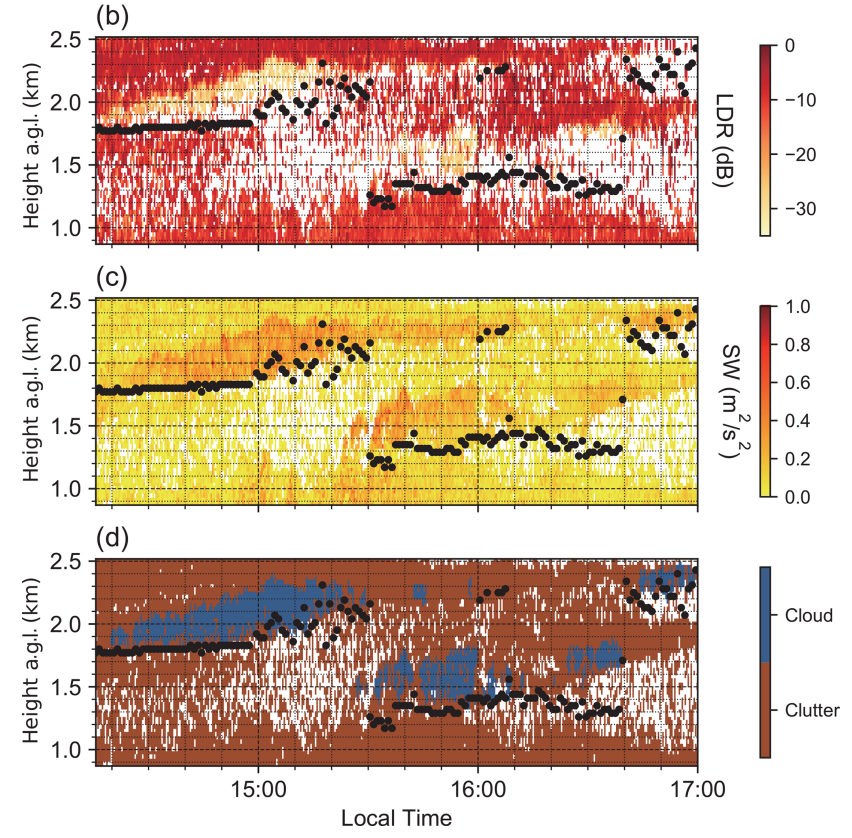

Figure 12. Same as Fig. 8 but for 14:15 to 17:00 LT on 19 August 2013.

ent from that, by using multi-dimensional PDFs with the Bayesian method, it can correctly identify cloud-like clutter and clutter-like cloud; thus, they increase the accuracy of the classification mask. Both $P_{\mathrm{D}}$ and $P_{\mathrm{FA}}$ are less fluctuating with time (Fig. 14d) and height (Fig. 14e) compared with the three radar variables (Fig. 14a-c), except for $P_{\mathrm{D}}$ above $3.2 \mathrm{~km}$, where the clutter is extremely rare (fewer samples). This indicates that the time and height variations of cloud and clutter features are well captured by the multi-dimensional PDFs. The $P_{\mathrm{D}}$ and $P_{\mathrm{FA}}$ of the whole year (black lines) are more consistent with that of warm season (red line), because clutter more frequently appears in the warm season. Overall, the 1-year evaluation shows that the algorithm can successfully filter clutter out with a high value of $P_{\mathrm{D}}(98.45 \%)$ and a very low value of $P_{\mathrm{FA}}(0.37 \%)$, as shown in Fig. 14f.

\section{Summary and discussion}

We develop a low-level cloud and clutter discrimination algorithm for a ground-based cloud radar based on multidimensional PDFs with the Bayesian method using cloud radar reflectivity, LDR, SW, and their time of the day, height, and season dependence as discriminants. A low-pass spa-
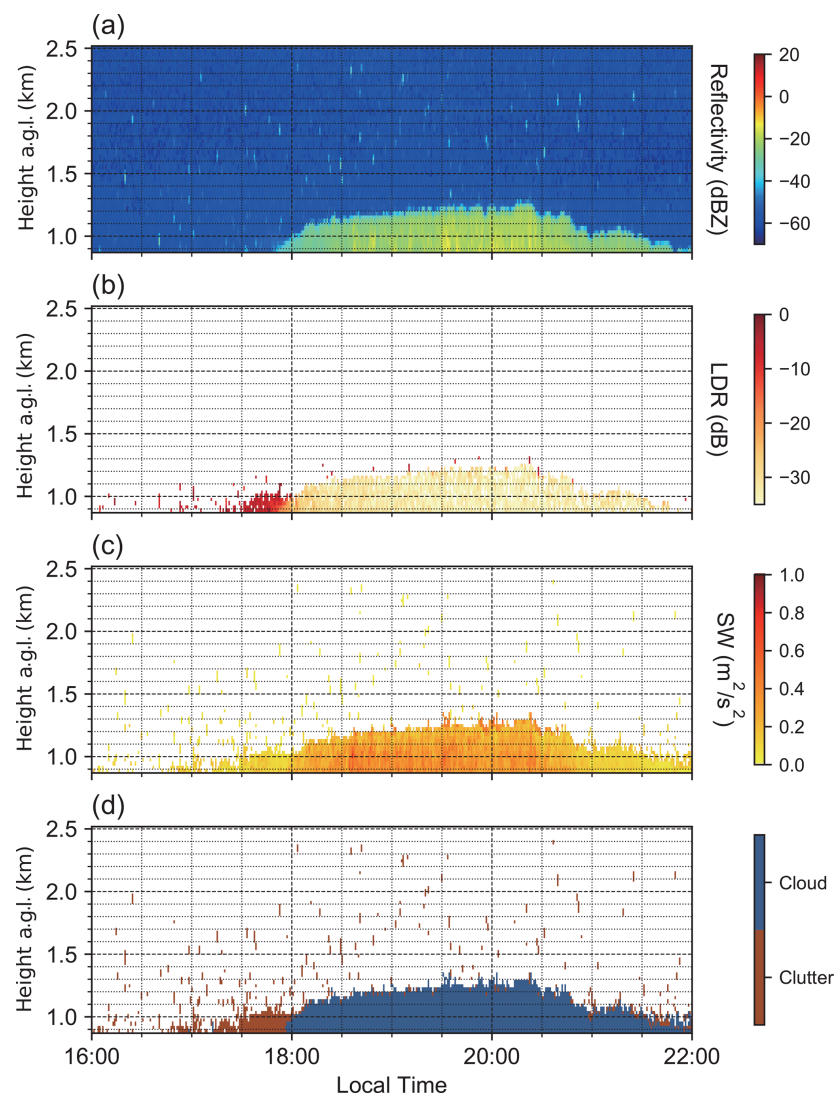

Figure 13. Same as Fig. 8 but for 16:00 to 22:00 LT on 4 February 2014. Note that the lidar observation is missed that day.

tial filter is applied to the Bayesian undecided classification mask, considering the spatial correlation difference between clouds and clutter. The case studies indicate the algorithm can filter out most of the clutter while still maintaining the low-level clouds (including drizzle), even when they are embedded in clutter layer. Unlike the traditional way of selecting a single LDR threshold to remove the clutter, this algorithm particularly shows higher accuracy for clutter-like clouds or cloud-like clutter. The 1-year evaluation demonstrates the good performance of this algorithm $(98.5 \%$ detection rate and $0.4 \%$ false alarm rate). For the quantitative evaluation, the lidar-detected cloud base is assumed to be perfectly correct, and the small temporal and spatial offsets between the radar and lidar are assumed to have a small impact. We conclude that this algorithm satisfactorily retains low-level clouds and removes radar clutter at the SACOL site.

For the non-cloud low-level meteorological target, such as precipitation and melting layer, we use radar observation itself to identify them (Chandra et al., 2015; Matrosov et al., 2007). Although it might not be as reliable as the method by combining the radar with other instruments such as rain gauge, it would still be enough to effectively reduce the misclassification of clutter and clouds. The more accurate esti- 

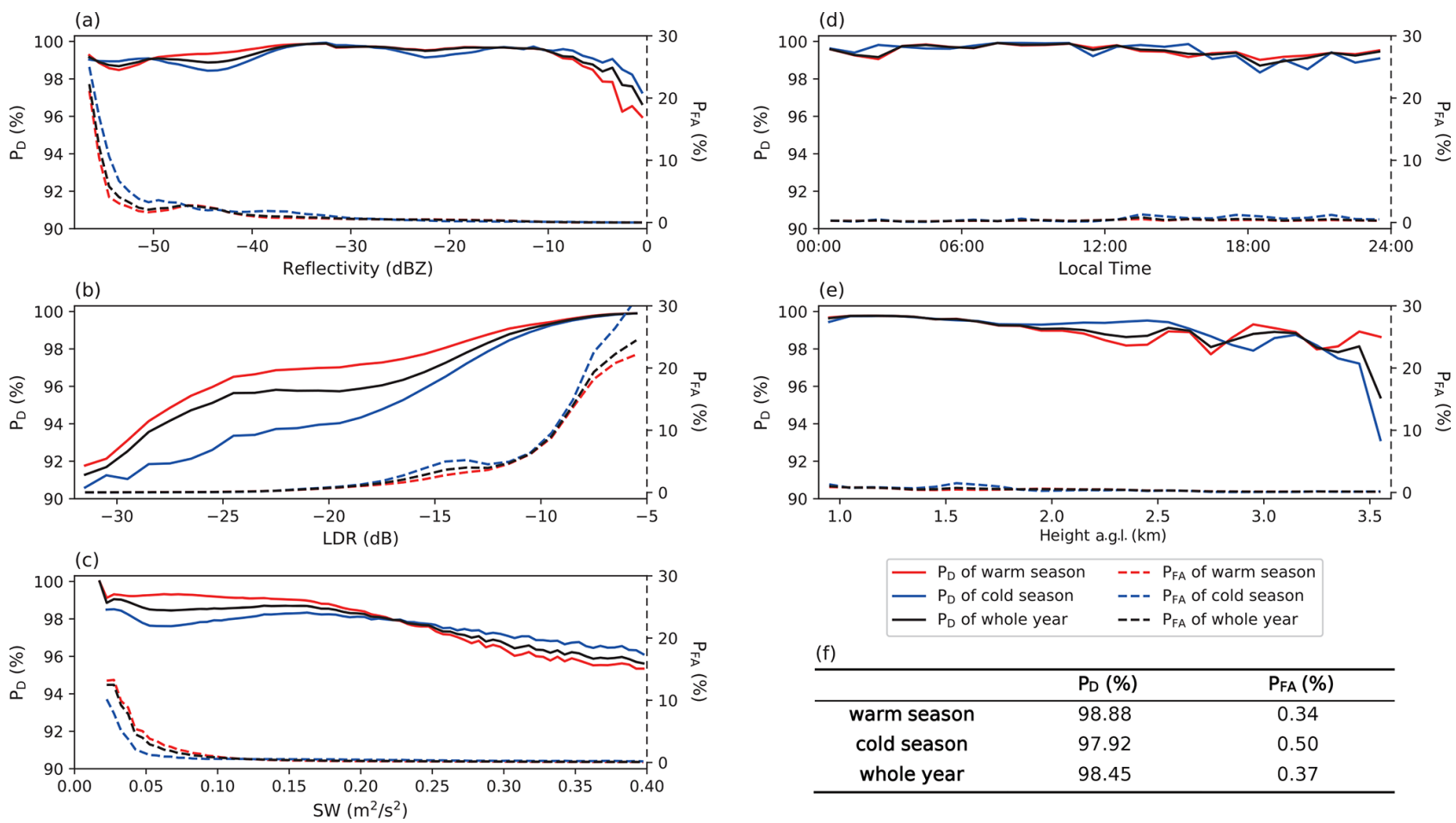

Figure 14. Probability of detection $\left(P_{\mathrm{D}}\right.$, solid line) and false alarm rate $\left(P_{\mathrm{FA}}\right.$, dashed line) as function of reflectivity (a), LDR (b), SW (c), time (d), and height (e) for the warm season (red line), cold season (blue line), and whole year (black line). The values of $P_{\mathrm{D}}$ and $P_{\mathrm{FA}}$ for the warm season, cold season, and whole year are shown in panel (f).

mation of rain rate will be carried out in our future work, along with this algorithm, used to provide more reliable lowlevel cloud and precipitation radar data to study its climate effect and the interaction with local abundant dust aerosol in semi-arid regions.

Data availability. Both the lidar and radar data used in this study can be acquired from the SACOL site (http://climate.lzu.edu.cn) (SACOL, 2021).

Author contributions. XH and JG designed the study. XH, JD, and QL performed the cloud and clutter discrimination. JH and QF discussed the method and the results. $\mathrm{XH}$ and JG prepared the manuscript with significant contributions from all co-authors.

Competing interests. The authors declare that they have no conflict of interest.

Acknowledgements. The authors would like to thank the SACOL team (http://climate.lzu.edu.cn, last access: 23 February 2021) for supporting the radar and lidar data. The authors would like to thank the three anonymous referees for the constructive comments. The authors would also like to thank Brian Kahn, the handling associate editor, and Andreas Richter, the handling executive editor, for all the support

Financial support. This research has been supported by the National Science Foundation of China (grant nos. 41922032, 41875028, and 91937302) and the National Key R \& D Program of China (grant no. 2016YFC0401003).

Review statement. This paper was edited by Brian Kahn and reviewed by three anonymous referees.

\section{References}

Abrol, D. P.: Diversity of pollinating insects visiting litchi flowers (Litchi chinensis Sonn.) and path analysis of environmental factors influencing foraging behaviour of four honeybee species, J. Apicult. Res., 45, 180-187, https://doi.org/10.1080/00218839.2006.11101345, 2015.

Arulraj, M. and Barros, A. P.: Shallow Precipitation Detection and Classification Using Multifrequency Radar Observations and Model Simulations, J. Atmos. Ocean. Tech., 34, 1963-1983, https://doi.org/10.1175/jtech-d-17-0060.1, 2017.

Bala, G., Caldeira, K., Nemani, R., Cao, L., Ban-Weiss, G., and Shin, H.-J.: Albedo enhancement of marine clouds to counteract global warming: impacts on the hydrological cycle, Clim. Dy- 
nam., 37, 915-931, https://doi.org/10.1007/s00382-010-0868-1, 2010.

Baldini, L. and Gorgucci, E.: Identification of the Melting Layer through Dual-Polarization Radar Measurements at Vertical Incidence, J. Atmos. Ocean. Tech., 23, 829-839, https://doi.org/10.1175/jtech1884.1, 2006.

Bony, S., Stevens, B., Frierson, D. M. W., Jakob, C., Kageyama, M., Pincus, R., Shepherd, T. G., Sherwood, S. C., Siebesma, A. P., Sobel, A. H., Watanabe, M., and Webb, M. J.: Clouds, circulation and climate sensitivity, Nat. Geosci., 8, 261-268, https://doi.org/10.1038/ngeo2398, 2015.

Brandes, E. A. and Ikeda, K.: Freezing-Level Estimation with Polarimetric Radar, J. Appl. Meteorol., 43, 1541-1553, https://doi.org/10.1175/jam2155.1, 2004.

Brient, F. and Bony, S.: Interpretation of the positive low-cloud feedback predicted by a climate model under global warming, Clim. Dynam., 40, 2415-2431, https://doi.org/10.1007/s00382011-1279-7, 2012.

Ceppi, P., Hartmann, D. L., and Webb, M. J.: Mechanisms of the Negative Shortwave Cloud Feedback in Middle to High Latitudes, J. Climate, 29, 139-157, https://doi.org/10.1175/jcli-d-150327.1, 2016.

Chandra, A., Zhang, C., Kollias, P., Matrosov, S., and Szyrmer, W.: Automated rain rate estimates using the Ka-band ARM zenith radar (KAZR), Atmos. Meas. Tech., 8, 3685-3699, https://doi.org/10.5194/amt-8-3685-2015, 2015.

Chapman, J. W., Reynolds, D. R., Wilson, K., and Holyoak, M.: Long-range seasonal migration in insects: mechanisms, evolutionary drivers and ecological consequences, Ecol. Lett., 18, 287-302, https://doi.org/10.1111/ele.12407, 2015.

Chernykh, I. V., Alduchov, O. A., and Eskridge, R. E.: Trends in Low and High Cloud Boundaries and Errors in Height Determination of Cloud Boundaries, B. Am. Meteorol. Soc., 82, 1941-1947, https://doi.org/10.1175/15200477(2001)082<1941:Tilahc>2.3.Co;2, 2001.

Clothiaux, E. E., Ackerman, T. P., Mace, G. G., Moran, K. P., Marchand, R. T., Miller, M. A., and Martner, B. E.: Objective Determination of Cloud Heights and Radar Reflectivities Using a Combination of Active Remote Sensors at the ARM CART Sites, J. Appl. Meteorol., 39, 645-665, https://doi.org/10.1175/15200450(2000)039<0645:odocha>2.0.co;2, 2000.

Devisetty, H. K., Jha, A. K., Das, S. K., Deshpande, S. M., Krishna, U. V. M., Kalekar, P. M., and Pandithurai, G.: A case study on bright band transition from very light to heavy rain using simultaneous observations of collocated X- and Ka-band radars, J. Earth Syst. Sci., 128, 136, https://doi.org/10.1007/s12040-0191171-0, 2019.

Fu, Q. and Feng, S.: Responses of terrestrial aridity to global warming, J. Geophys. Res.-Atmos., 119, 7863-7875, https://doi.org/10.1002/2014jd021608, 2014

Fu, Q., Carlin, B., and Mace, G.: Cirrus horizontal inhomogeneity and OLR bias, Geophys. Res. Lett., 27, 3341-3344, https://doi.org/10.1029/2000g1011944, 2000.

Fu, Q., Baker, M., and Hartmann, D. L.: Tropical cirrus and water vapor: an effective Earth infrared iris feedback?, Atmos. Chem. Phys., 2, 31-37, https://doi.org/10.5194/acp-2-31-2002, 2002.

Fu, Q., Smith, M., and Yang, Q.: The Impact of Cloud Radiative Effects on the Tropical Tropopause
Layer Temperatures, Atmosphere-Basel, 9, 377 , https://doi.org/10.3390/atmos9100377, 2018.

Garrett, T. J. and Zhao, C.: Ground-based remote sensing of thin clouds in the Arctic, Atmos. Meas. Tech., 6, 1227-1243, https://doi.org/10.5194/amt-6-1227-2013, 2013.

Ge, J., Zhu, Z., Zheng, C., Xie, H., Zhou, T., Huang, J., and Fu, Q.: An improved hydrometeor detection method for millimeterwavelength cloud radar, Atmos. Chem. Phys., 17, 9035-9047, https://doi.org/10.5194/acp-17-9035-2017, 2017.

Ge, J., Zheng, C., Xie, H., Xin, Y., Huang, J., and Fu, Q.: Midlatitude Cirrus Clouds at the SACOL Site: Macrophysical Properties and Large-Scale Atmospheric States, J. Geophys. Res.-Atmos., 123, 2256-2271, https://doi.org/10.1002/2017jd027724, 2018.

Ge, J., Wang, Z., Liu, Y., Su, J., Wang, C., and Dong, Z.: Linkages between mid-latitude cirrus cloud properties and large-scale meteorology at the SACOL site, Clim. Dynam., 53, 5035-5046, https://doi.org/10.1007/s00382-019-04843-9, 2019.

Ge, J. M., Huang, J. P., Xu, C. P., Qi, Y. L., and Liu, H. Y.: Characteristics of Taklimakan dust emission and distribution: A satellite and reanalysis field perspective, J. Geophys. Res.-Atmos., 119, 11772-11783, https://doi.org/10.1002/2014jd022280, 2014.

Geerts, B. and Miao, Q.: The Use of Millimeter Doppler Radar Echoes to Estimate Vertical Air Velocities in the Fair-Weather Convective Boundary Layer, J. Atmos. Ocean. Tech., 22, 225246, https://doi.org/10.1175/jtech1699.1, 2005.

Givati, A. and Rosenfeld, D.: Quantifying Precipitation Suppression Due to Air Pollution, J. Appl. Meteorol., 43, 1038-1056, https://doi.org/10.1175/15200450(2004)043<1038:Qpsdta>2.0.Co;2, 2004.

Golbon-Haghighi, M.-H., Zhang, G., Li, Y., and Doviak, R.: Detection of Ground Clutter from Weather Radar Using a Dual-Polarization and Dual-Scan Method, Atmosphere, 7, 83, https://doi.org/10.3390/atmos7060083, 2016.

Görsdorf, U., Lehmann, V., Bauer-Pfundstein, M., Peters, G., Vavriv, D., Vinogradov, V., and Volkov, V.: A 35-GHz Polarimetric Doppler Radar for Long-Term Observations of Cloud Parameters - Description of System and Data Processing, J. Atmos. Ocean. Tech., 32, 675-690, https://doi.org/10.1175/jtechd-14-00066.1, 2015.

Harrison, R. G., Nicoll, K. A., and Aplin, K. L.: Evaluating stratiform cloud base charge remotely, Geophys. Res. Lett., 44, 64076412, https://doi.org/10.1002/2017gl073128, 2017.

Hu, X., Ge, J., Li, Y., Marchand, R., Huang, J., and Fu, Q.: Improved Hydrometeor Detection Method: An Application to CloudSat, Earth Space Sci., 7, e2019EA000900, https://doi.org/10.1029/2019ea000900, 2020.

Huang, J., Ge, J., and Weng, F.: Detection of Asia dust storms using multisensor satellite measurements, Remote Sens. Environ., 110, 186-191, https://doi.org/10.1016/j.rse.2007.02.022, 2007.

Huang, J., Huang, Z., Bi, J., Zhang, W., and Zhang, L.: Micro-Pulse Lidar Measurements of Aerosol Vertical Structure over the Loess Plateau, Atmos. Ocean. Sci. Lett., 1, 8-11, https://doi.org/10.1080/16742834.2008.11446756, 2008a.

Huang, J., Zhang, W., Zuo, J., Bi, J., Shi, J., Wang, X., Chang, Z., Huang, Z., Yang, S., Zhang, B., Wang, G., Feng, G., Yuan, J., Zhang, L., Zuo, H., Wang, S., Fu, C., and Chou, J.: An Overview of the Semi-arid Climate and Environment Research Observatory over the Loess Plateau, Adv. Atmos. Sci., 25, 906-921, https://doi.org/10.1007/s00376-008-0906-7, 2008b. 
Huang, J., Yu, H., Dai, A., Wei, Y., and Kang, L.: Drylands face potential threat under $2{ }^{\circ} \mathrm{C}$ global warming target, Nat. Clim. Change, 7, 417-422, https://doi.org/10.1038/nclimate3275, 2017.

Huang, J., Huang, J., Liu, X., Li, C., Ding, L., and Yu, H.: The global oxygen budget and its future projection, Sci. Bull., 63, 1180-1186, https://doi.org/10.1016/j.scib.2018.07.023, 2018.

Huang, J., Zhang, G., Zhang, Y., Guan, X., Wei, Y., and Guo, R.: Global desertification vulnerability to climate change and human activities, Land Degrad. Dev., 31, 1380-1391, https://doi.org/10.1002/ldr.3556, 2020.

Huang, J. P., Lin, B., Minnis, P., Wang, T., Wang, X., $\mathrm{Hu}$, Y., Yi, Y., and Ayers, J. K.: Satellite-based assessment of possible dust aerosols semi-direct effect on cloud water path over East Asia, Geophys. Res. Lett., 33, L19802, https://doi.org/10.1029/2006g1026561, 2006.

Huang, J. P., Wang, T., Wang, W., Li, Z., and Yan, H.: Climate effects of dust aerosols over East Asian arid and semiarid regions, J. Geophys. Res.-Atmos., 119, 11398-11416, https://doi.org/10.1002/2014jd021796, 2014.

Hubbert, J. C., Wilson, J. W., Weckwerth, T. M., Ellis, S. M., Dixon, M., and Loew, E.: S-Pol's Polarimetric Data Reveal Detailed Storm Features (and Insect Behavior), B. Am. Meteorol. Soc., 99, 2045-2060, https://doi.org/10.1175/bams-d-17-0317.1, 2018.

Huo, J., Lu, D., Duan, S., Bi, Y., and Liu, B.: Comparison of the cloud top heights retrieved from MODIS and AHI satellite data with ground-based Ka-band radar, Atmos. Meas. Tech., 13, 1-11, https://doi.org/10.5194/amt-13-1-2020, 2020.

Islam, T., Rico-Ramirez, M. A., Han, D., Bray, M., and Srivastava, P. K.: Fuzzy logic based melting layer recognition from $3 \mathrm{GHz}$ dual polarization radar: appraisal with NWP model and radio sounding observations, Theor. Appl. Climatol., 112, 317338, https://doi.org/10.1007/s00704-012-0721-z, 2012.

Jing $\mathrm{Su}$, Jianping Huang, Qiang Fu, Minnis, P., Jinming Ge, and Jianrong Bi: Estimation of Asian dust aerosol effect on cloud radiation forcing using Fu-Liou radiative model and CERES measurements, Atmos. Chem. Phys., 8, 2763-2771, https://doi.org/10.5194/acp-8-2763-2008, 2008.

Johnson, C. A., Coutinho, R. M., Berlin, E., Dolphin, K. E., Heyer, J., Kim, B., Leung, A., Sabellon, J. L., Amarasekare, P., and Carroll, S.: Effects of temperature and resource variation on insect population dynamics: the bordered plant bug as a case study, Funct. Ecol., 30, 1122-1131, https://doi.org/10.1111/1365-2435.12583, 2016.

Johnson, K., Toto, T., and Giangrande, S.: Ka-Band ARM Zenith Radar Corrections Value-Added Product, U.S. Department of Energy, Washington, DC, 2017.

Kalapureddy, M. C. R., Sukanya, P., Das, S. K., Deshpande, S. M., Pandithurai, G., Pazamany, A. L., Ambuj K., J., Chakravarty, K., Kalekar, P., Devisetty, H. K., and Annam, S.: A simple biota removal algorithm for $35 \mathrm{GHz}$ cloud radar measurements, Atmos. Meas. Tech., 11, 1417-1436, https://doi.org/10.5194/amt11-1417-2018, 2018.

Khanal, A. K., Delrieu, G., Cazenave, F., and Boudevillain, B.: Radar Remote Sensing of Precipitation in High Mountains: Detection and Characterization of Melting Layer in the Grenoble Valley, French Alps, Atmosphere-Basel, 10, 784, https://doi.org/10.3390/atmos10120784, 2019.
Kim, S.-W., Chung, E.-S., Yoon, S.-C., Sohn, B.-J., and Sugimoto, N.: Intercomparisons of cloud-top and cloud-base heights from ground-based Lidar, CloudSat and CALIPSO measurements, Int. J. Remote Sens., 32, 1179-1197, https://doi.org/10.1080/01431160903527439, 2011.

Kollias, P., Clothiaux, E. E., Miller, M. A., Albrecht, B. A., Stephens, G. L., and Ackerman, T. P.: Millimeter-Wavelength Radars: New Frontier in Atmospheric Cloud and Precipitation Research, B. Am. Meteorol. Soc., 88, 1608-1624, https://doi.org/10.1175/bams-88-10-1608, 2007a.

Kollias, P., Clothiaux, E. E., Miller, M. A., Luke, E. P., Johnson, K. L., Moran, K. P., Widener, K. B., and Albrecht, B. A.: The Atmospheric Radiation Measurement Program Cloud Profiling Radars: Second-Generation Sampling Strategies, Processing, and Cloud Data Products, J. Atmos. Ocean. Tech., 24, 11991214, https://doi.org/10.1175/jtech2033.1, 2007b.

Kollias, P., Remillard, J., Luke, E., and Szyrmer, W.: Cloud radar Doppler spectra in drizzling stratiform clouds: 1. Forward modeling and remote sensing applications, J. Geophys. Res.-Atmos., 116, D13201, https://doi.org/10.1029/2010jd015237, 2011.

Kollias, P., Puigdomènech Treserras, B., and Protat, A.: Calibration of the 2007-2017 record of Atmospheric Radiation Measurements cloud radar observations using CloudSat, Atmos. Meas. Tech., 12, 4949-4964, https://doi.org/10.5194/amt-124949-2019, 2019.

Kowalewski, S. and Peters, G.: Analysis of $Z-R$ Relations Based on LDR Signatures within the Melting Layer, J. Atmos. Ocean. Tech., 27, 1555-1561, https://doi.org/10.1175/2010jtecha1363.1, 2010.

Linero, A. R. and Daniels, M. J.: Bayesian Approaches for Missing Not at Random Outcome Data: The Role of Identifying Restrictions, Stat. Sci., 33, 198-213, https://doi.org/10.1214/17-sts630, 2018.

Liu, Z., Vaughan, M. A., Winker, D. M., Hostetler, C. A., Poole, L. R., Hlavka, D., Hart, W., and McGill, M.: Use of probability distribution functions for discriminating between cloud and aerosol in lidar backscatter data, J. Geophys. Res., 109, D15202, https://doi.org/10.1029/2004jd004732, 2004.

Liu, Z., Vaughan, M., Winker, D., Kittaka, C., Getzewich, B., Kuehn, R., Omar, A., Powell, K., Trepte, C., and Hostetler, C.: The CALIPSO Lidar Cloud and Aerosol Discrimination: Version 2 Algorithm and Initial Assessment of Performance, J. Atmos. Ocean. Tech., 26, 1198-1213, https://doi.org/10.1175/2009jtecha1229.1, 2009.

Liu, Z., Kar, J., Zeng, S., Tackett, J., Vaughan, M., Avery, M., Pelon, J., Getzewich, B., Lee, K.-P., Magill, B., Omar, A., Lucker, P., Trepte, C., and Winker, D.: Discriminating between clouds and aerosols in the CALIOP version 4.1 data products, Atmos. Meas. Tech., 12, 703-734, https://doi.org/10.5194/amt12-703-2019, 2019.

Luke, E. P., Kollias, P., Johnson, K. L., and Clothiaux, E. E.: A technique for the automatic detection of insect clutter in cloud radar returns, J. Atmos. Ocean. Tech., 25, 1498-1513, https://doi.org/10.1175/2007jtecha953.1, 2008.

Ma, J., Hu, Z., Yang, M., and Li, S.: Improvement of X-Band Polarization Radar Melting Layer Recognition by the Bayesian Method and Its Impact on Hydrometeor Classification, Adv. Atmos. Sci., 37, 105-116, https://doi.org/10.1007/s00376-0199007-z, 2019. 
Mace, G. G. and Berry, E.: Using Active Remote Sensing to Evaluate Cloud-Climate Feedbacks: a Review and a Look to the Future, Current Climate Change Reports, 3, 185-192, https://doi.org/10.1007/s40641-017-0067-9, 2017.

Marchand, R., Mace, G. G., Ackerman, T., and Stephens, G.: Hydrometeor Detection UsingCloudsat - An Earth-Orbiting 94-GHz Cloud Radar, J. Atmos. Ocean. Tech., 25, 519-533, https://doi.org/10.1175/2007jtecha1006.1, 2008.

Martner, B. E. and Moran, K. P.: Using cloud radar polarization measurements to evaluate stratus cloud and insect echoes, J. Geophys. Res.-Atmos., 106, 4891-4897, https://doi.org/10.1029/2000jd900623, 2001.

Matrosov, S. Y., Clark, K. A., and Kingsmill, D. E.: A Polarimetric Radar Approach to Identify Rain, Melting-Layer, and Snow Regions for Applying Corrections to Vertical Profiles of Reflectivity, J. Appl. Meteorol. Clim., 46, 154-166, https://doi.org/10.1175/jam2508.1, 2007.

Nuijens, L., Emanuel, K., Masunaga, H., and L'Ecuyer, T.: Implications of Warm Rain in Shallow Cumulus and Congestus Clouds for Large-Scale Circulations, Surv. Geophys., 38, 1257-1282, https://doi.org/10.1007/s10712-017-9429-z, 2017.

O’Connor, E. J., Hogan, R. J., and Illingworth, A. J.: Retrieving Stratocumulus Drizzle Parameters Using Doppler Radar and Lidar, J. Appl. Meteorol., 44, 14-27, https://doi.org/10.1175/jam2181.1, 2005.

Oh, S.-B., Lee, Y. H., Jeong, J.-H., Kim, Y.-H., and Joo, S.: Estimation of the liquid water content and Z-LWC relationship using Ka-band cloud radar and a microwave radiometer, Meteorol. Appl., 25, 423-434, https://doi.org/10.1002/met.1710, 2018.

Perry, L. B., Seimon, A., Andrade-Flores, M. F., Endries, J. L., Yuter, S. E., Velarde, F., Arias, S., Bonshoms, M., Burton, E. J., Winkelmann, I. R., Cooper, C. M., Mamani, G., Rado, M., Montoya, N., and Quispe, N.: Characteristics of Precipitating Storms in Glacierized Tropical Andean Cordilleras of Peru and Bolivia, Ann. Am. Assoc. Geogr., 107, 309-322, https://doi.org/10.1080/24694452.2016.1260439, 2017.

Pinsky, M. and Khain, A.: Theoretical Analysis of the Entrainment-Mixing Process at Cloud Boundaries. Part II: Motion of Cloud Interface, J. Atmos. Sci., 76, 2599-2616, https://doi.org/10.1175/jas-d-18-0314.1, 2019.

Quaas, J., Quaas, M. F., Boucher, O., and Rickels, W.: Regional climate engineering by radiation management: Prerequisites and prospects, Earths Future, 4, 618-625, https://doi.org/10.1002/2016ef000440, 2016.

Rico-Ramirez, M. A. and Cluckie, I. D.: Classification of Ground Clutter and Anomalous Propagation Using Dual-Polarization Weather Radar, IEEE T. Geosci. Remote, 46, 1892-1904, https://doi.org/10.1109/tgrs.2008.916979, 2008.

SACOL: Homepage, available at: http://climate.lzu.edu.cn, last access: 23 February 2021.

Shupe, M. D.: A ground-based multisensor cloud phase classifier, Geophys. Res. Lett., 34, L22809, https://doi.org/10.1029/2007gl031008, 2007.

Sokol, Z., Minářová, J., and Novák, P.: Classification of Hydrometeors Using Measurements of the Ka-Band Cloud Radar Installed at the Milešovka Mountain (Central Europe), Remote Sens.Basel, 10, 1674, https://doi.org/10.3390/rs10111674, 2018.

Terai, C. R., Klein, S. A., and Zelinka, M. D.: Constraining the lowcloud optical depth feedback at middle and high latitudes using satellite observations, J. Geophys. Res.-Atmos., 121, 9696-9716, https://doi.org/10.1002/2016jd025233, 2016.

Thomas, C. F. G., Brain, P., and Jepson, P. C.: Aerial activity of linyphiid spiders: modelling dispersal distances from meteorology and behaviour, J. Appl. Ecol., 40, 912-927, https://doi.org/10.1046/j.1365-2664.2003.00844.x, 2003.

Toll, V., Christensen, M., Quaas, J., and Bellouin, N.: Weak average liquid-cloud-water response to anthropogenic aerosols, Nature, 572, 51-55, https://doi.org/10.1038/s41586-019-1423-9, 2019.

Turner, D. D., Vogelmann, A. M., Austin, R. T., Barnard, J. C., Cady-Pereira, K., Chiu, J. C., Clough, S. A., Flynn, C., Khaiyer, M. M., Liljegren, J., Johnson, K., Lin, B., Long, C., Marshak, A., Matrosov, S. Y., McFarlane, S. A., Miller, M., Min, Q., Minimis, P., O'Hirok, W., Wang, Z., and Wiscombe, W.: Thin Liquid Water Clouds: Their Importance and Our Challenge, B. Am. Meteorol. Soc., 88, 177-190, https://doi.org/10.1175/bams-88-2-177, 2007.

van der Linden, R., Fink, A. H., and Redl, R.: Satellite-based climatology of low-level continental clouds in southern West Africa during the summer monsoon season, J. Geophys. Res.-Atmos., 120, 1186-1201, https://doi.org/10.1002/2014jd022614, 2015.

Watanabe, M., Kamae, Y., Shiogama, H., DeAngelis, A. M., and Suzuki, K.: Low clouds link equilibrium climate sensitivity to hydrological sensitivity, Nat. Clim. Change, 8, 901-906, https://doi.org/10.1038/s41558-018-0272-0, 2018.

Williams, C. R., Maahn, M., Hardin, J. C., and de Boer, G.: Clutter mitigation, multiple peaks, and high-order spectral moments in $35 \mathrm{GHz}$ vertically pointing radar velocity spectra, Atmos. Meas. Tech., 11, 4963-4980, https://doi.org/10.5194/amt11-4963-2018, 2018.

Wood, C. R., O'Connor, E. J., Hurley, R. A., Reynolds, D. R., and Illingworth, A. J.: Cloud-radar observations of insects in the UK convective boundary layer, Meteorol. Appl., 16, 491-500, https://doi.org/10.1002/met.146, 2009.

Wu, P., Dong, X., and Xi, B.: Marine boundary layer drizzle properties and their impact on cloud property retrieval, Atmos. Meas. Tech., 8, 3555-3562, https://doi.org/10.5194/amt-8-3555-2015, 2015.

Xie, H., Zhou, T., Fu, Q., Huang, J., Huang, Z., Bi, J., Shi, J., Zhang, B., and Ge, J.: Automated detection of cloud and aerosol features with SACOL micro-pulse lidar in northwest China, Opt. Express, 25, 30732-30753, https://doi.org/10.1364/oe.25.030732, 2017.

Xin, Y., Su, J., Li, X., Hu, X., Ge, J., and Fu, Q.: Retrieval of ice cloud microphysical properties at the SACOL, Chinese Sci. Bull., 64, 2728-2740, https://doi.org/10.1360/n972019-00104, 2019.

Xue, H., Feingold, G., and Stevens, B.: Aerosol Effects on Clouds, Precipitation, and the Organization of Shallow Cumulus Convection, J. Atmos. Sci., 65, 392-406, https://doi.org/10.1175/2007jas2428.1, 2008.

Yang, F., Luke, E. P., Kollias, P., Kostinski, A. B., and Vogelmann, A. M.: Scaling of Drizzle Virga Depth With Cloud Thickness for Marine Stratocumulus Clouds, Geophys. Res. Lett., 45, 3746-3753, https://doi.org/10.1029/2018gl077145, 2018.

Zelinka, M. D., Myers, T. A., McCoy, D. T., Po-Chedley, S., Caldwell, P. M., Ceppi, P., Klein, S. A., and Taylor, K. E.: Causes of Higher Climate Sensitivity in 
CMIP6 Models, Geophys. Res. Lett., 47, e2019GL085782, https://doi.org/10.1029/2019gl085782, 2020.

Zhang, H., Wang, M., Guo, Z., Zhou, C., Zhou, T., Qian, Y., Larson, V. E., Ghan, S., Ovchinnikov, M., Bogenschutz, P. A., and Gettelman, A.: Low-Cloud Feedback in CAM5CLUBB: Physical Mechanisms and Parameter Sensitivity Analysis, J. Adv. Model. Earth Sy., 10, 2844-2864, https://doi.org/10.1029/2018ms001423, 2018.
Zheng, J., Liu, L., Zhu, K., Wu, J., and Wang, B.: A Method for Retrieving Vertical Air Velocities in Convective Clouds over the Tibetan Plateau from TIPEX-III Cloud Radar Doppler Spectra, Remote Sens.-Basel, 9, 964, https://doi.org/10.3390/rs9090964, 2017.

Zhu, Z., Zheng, C., Ge, J., Huang, J., and Fu, Q.: Cloud macrophysical properties from KAZR at the SACOL, Chinese Sci. Bull., 62, 824-835, https://doi.org/10.1360/n972016-00857, 2017. 